DEPARTMENT OF ECONOMICS WORKING PAPER SERIES

\title{
Business cycles, financial conditions and nonlinearities
}

\author{
Ivan Mendieta-Muñoz \\ Doğuhan Sündal
}

Working Paper No: 2020-04

May 2020

\author{
University of Utah \\ Department of Economics \\ 260 S. Central Campus Dr., GC. 4100 \\ Tel: (801) 581-7481 \\ Fax: (801) 585-5649 \\ http://www.econ.utah.edu
}




\title{
Business cycles, financial conditions and nonlinearities
}

\author{
Ivan Mendieta-Muñoz \\ Department of Economics, University of Utah \\ ivan.mendietamunoz@utah.edu \\ Doğuhan Sündal \\ Department of Economics, University of Utah \\ doguhan.sundal@utah.edu
}

\begin{abstract}
This paper proposes a conceptualization of business cycle fluctuations in which the role of financial conditions and nonlinear dynamics are explicitly incorporated. We highlight the role of investment demand in driving economic fluctuations, consider its endogenous dynamic interactions with profitability and aggregate demand levels as well as financial conditions, emphasize that the sources of instability in an economy cannot be associated exclusively with the real or financial sectors, and incorporate the idea that financial conditions are both important sources of instability and possible nonlinear propagators of other sources of instability. We test the propagation mechanisms of such conceptualization using a Bayesian Threshold Vector Autoregression model for the US economy. The results support the characterization of nonlinear dynamics in the transmission of shocks since there is evidence of asymmetric responses of the variables across two different regimes of financial stress, responding more strongly during loose financial conditions.
\end{abstract}

Keywords: Business cycles; investment fluctuations; financial conditions; nonlinear dynamics; Bayesian Threshold Vector Autoregression.

JEL Classification: B50; E10; E22; E32; E43. 


\section{Introduction}

The study of the nature of business cycle fluctuations and of its propagation mechanisms are topics of paramount importance in order to understand short-run changes in economic activity and to provide economic policies that respond adequately to such endogenous events. Numerous conceptualizations have been proposed from alternative theoretical and empirical approaches; but considerable uncertainty regarding the appropriate characterization of economic fluctuations remains since there is ample controversy about the origins of the latter.

This paper proposes a characterization of business cycle fluctuations that highlights the role of investment demand in this process; stresses that the sources of instability in an economy cannot be identified exclusively with the real or financial sectors; and emphasizes the importance of nonlinear dynamics to study the propagation mechanisms in the short-run. In brief, we posit that business cycles are appropriately captured by the endogenous dynamic interactions between investment decisions, profitability and aggregate demand levels, and financial conditions; and we explicitly incorporate the idea that the latter are both important sources of instability and possible nonlinear propagators of other sources of instability in the economy. We study the empirical relevance of such conceptualization using a Threshold Vector Autoregression model for the US economy - which enables us to deal jointly with the endogenous interactions between the variables and to identify nonlinear responses to endogenous shocks, thus capturing the dynamic responses of the variables across two different regimes associated with an indicator of financial conditions. The model is estimated using a Bayesian sampling algorithm in order to incorporate relevant prior information in our estimation and to improve the computation of the estimates - that is, coefficients and variances of the model, and the threshold value for financial conditions.

Main results can be summarized as follows. We find significant evidence supporting the characterization of nonlinear dynamics in the transmission of shocks since there are asymmetric responses of all variables associated with different levels of financial stress. Shocks to the economic system generate more persistent responses of the endogenous variables when the economy is in a regime associated with loose financial conditions compared with the situation in which the economy is in a regime defined by tight financial conditions. This result is robust to different conceptualizations of the propagation of shocks in the short-run - assuming that the variable capturing financial tightness or the variable capturing aggregate demand pressures is the first one that is affected; and imply that providing a more prominent role to financial conditions and the nonlinearities arising from the interactions between real and financial sectors represents a highly promising avenue in order to characterize fluctuations in economic activity.

Besides this Introduction, the rest of the paper includes five sections. Section 2 motivates the current research by presenting a selected literature review. Section 3 motivates the model specification in light of the discussion presented in Section 2. Section 4 discusses the main technical details with regard to our econometric technique; while Section 5 summarizes and discusses the main empirical results. Finally, Section 6 presents our conclusions. 


\section{Background and motivation}

Our contribution is related, first, to the study of business cycles within the heterodox tradition in economics and, specifically, to those contributions that have emphasized: (i) the importance of investment demand in driving economic fluctuations since it represents the most volatile component of aggregate demand and because of its direct role in the accumulation of capital; and (ii) that the sources of instability in a capitalist economy cannot be associated exclusively with the real or financial sectors of the economy, highlighting that deteriorating financial conditions can act as a major factor affecting real economic activity and the importance of capitalists' risk perception for investment decisions.

With respect to the former, the contributions by Marglin and Bhaduri (1992) and Basu et al. (2013) stand out because of its emphasis on the relationship between the system of production and the macroeconomic structure-namely, the role of profitability in determining investment demand and the level of economic activity, and the role of class conflict between capitalists and workers over the distribution of income. Marglin and Bhaduri (1992)'s main argument can be summarized as follows. When the level of economic activity is high, employment and real wages grow and the growth of labor productivity is inhibited, which puts downward pressure on profits, and a reduction in investment together with a crisis of accumulation may arise. They highlighted the structural changes that have taken place in most industrialized countries, maintaining that the cornerstone of the phase of cooperative capitalism - induced by high labor shares of income and implemented until the demise of the Golden Age - was Keynesian in nature since aggregate demand deficiencies are central ingredients of the story, and that class conflict tensions have once again emerged since the 1980s when profitability had declined.

Basu et al. (2013) discuss a similar mechanism, which can be considered an extension of the traditional cyclical profit squeeze mechanism (CPS) because of its emphasis on investment demand fluctuations. ${ }^{1}$ During the recovery phase of a business cycle, the demand for labor-power and employment rise, and the labor market tightens. There is an increase in the relative bargaining power of labor with respect to capital, and real wages (labor costs) rise relative to labor productivity. Competition constraints the ability of firms

\footnotetext{
${ }^{1}$ There is an enormous body of literature highlighting the role of class struggle and the conflict between capitalists and workers over the distribution of income as a relevant mechanism in order to understand business cycle fluctuations. The CPS mechanism goes back to the discussion provided by Marx (1867) in the first volume of Capital (Chapter 25); and selected contributions include Goodwin (1967)'s seminal mathematical model; Boddy and Crotty (1975), who showed its empirical relevance; the series of important theoretical and empirical contributions by Goldstein (1985, 1999a,b, 2002); and Bakir and Campbell (2006), who found some evidence supporting the CPS mechanism during the neoliberal period. The CPS mechanism has also received numerous criticisms, such as Sherman $(1972,1997)$ - who highlighted the importance of demand side factors to complement the reliance on supply side factors, cyclical under-consumption and induced squeeze of profits associated with non-labor costs; and Michl (1988), Epstein (1991) and Weisskopf (1992) - who were skeptical about the efficacy of the CPS in explaining business cycles under neoliberal capitalism because the latter has reduced the relative bargaining power of labor, making profit squeeze of economic fluctuations less plausible during recent decades. Basu et al. (2013) offer a comprehensive discussion of this literature; while discussions about the recent literature on the interactions between income distribution and economic activity can be found in Kiefer and Rada (2015), von Arnim and Barrales (2015), Rada and Kiefer (2016) and Barrales and von Arnim (2017).
} 
to raise prices, and, therefore, the relative shares of national income change from mid-expansion onward: the profit (labor) share of income declines (increases). Since a falling profit share can impact negatively the investment decisions of capitalist firms via lower current and future expected profitability and declining cash flows, close to the peak of the economic expansion investment falls, so there is a contraction in the demand for labor-power and employment, and the labor market loosens. ${ }^{2}$ The relative bargaining power of workers vis-á-vis capitalists falls and, hence, real wages fall relative to productivity growth, so the profit (labor) share increases (decreases) and, eventually, the economy is ready for another business cycle. Basu et al. (2013) tested the relevance of this mechanism using a Vector Autoregression (VAR) model, finding empirical evidence supporting such business cycle fluctuations both during the regulated phase of post-World War II U.S. capitalism and the neoliberal period.

Other important contributions to political economy have discussed that the sources of instability in a capitalist economy cannot be associated exclusively with the real or financial sectors. ${ }^{3}$ Crotty (1990) presents a clear conceptual discussion of the possible endogenous interactions between real and financial variables in connection with investment decisions. He discusses that theories of capitalist economic fluctuations can be regarded as theories of endogenous instability - which stress that the main sources of instability can be found either in the real sector or in the financial sector ${ }^{4}$ - or theories that consider the existence of multiple equilibria states or paths; and he stresses that monocausal theories in which the root of instability can be identified exclusively with the financial or the real sector are incomplete.

Following Keynes' work, Crotty (1990) considers that: (a) the current production cost of capital and the instability of the marginal efficiency of capital are the main factors affecting investment decisions; (b) the two main indicators affecting the expected rate of profit on capital are the direct estimates made by the managers of the firm and the stockholders' expected profitability implicit in the financial market value of the firm; and (c) stockholders and managers have different objectives and planning time horizons, different information and, therefore, different estimates of the yield on capital. In Keynes' view, when the two main indicators determining the expected rate of profit on capital offer conflicting signals, perspectives on the stock market prevail and, thus, stockholders dominate managers. Hence, stockholders - and not managers - determine investment when there is a conflict and, since financial markets are unstable and the underlying performance of the marginal efficiency of capital is influenced by these markets, investment (which is determined by the marginal efficiency of capital) also exhibits instability. ${ }^{5}$

\footnotetext{
${ }^{2}$ Other contributions to the mainstream literature have also recently emphasized the importance of profitability for investment decisions. For example, Chapter 15 in Blanchard (2017) stresses the importance of profits for investment decisions by explicitly incorporating a positive effect of the expected present value of future profits per unit of capital on the investment-to-capital ratio.

${ }^{3}$ Marx (1894), Keynes (1936), Kalecki (1971) and Minsky (1986) represent notable examples of earlier contributions to the study of the endogenous interactions between financial conditions and economic activity.

${ }^{4}$ These could be Keynes-inspired (where models have no real-sector impediments to equilibrium and source of instability can be found in financial-markets), Keynesian multiplier-accelerator models (in which financial markets are either neglected or of secondary importance), or Marx-inspired (where models focus mainly on real-sector impediments to balanced growth).

${ }^{5}$ Crotty (1990) also notes that the stockholders' view on the marginal efficiency of capital dominating
} 
Crotty (1990) points out that, nowadays, institutions (not individuals) own the majority of stock and dominate stock trading, and that these institutions turn over most of their portfolios in the course of a year. This is important as it implies that there are no long-term stockholders anymore and, in contrast to managers, stockholders care about shorter-term returns, and they will not have (or do not pay attention to) the higher-quality information about the expected profitability of a prospective capital investment. As a result, there can be important differences between stockholder-oriented and manager-oriented investment policies: (a) stockholders tend to tolerate corporation-specific risk more than managers; (b) managers could invest more than the level which maximizes return on equities; (c) since managers focus more on long-term horizons and are more risk averse when it comes to accumulation of tangible, illiquid assets, investment may be less sensitive to short-term changes in stock prices (or other financial measures, such as Tobin's Q); and (d) stockholders and managers could respond differently to competitive pressures, as managers will increase cost-cutting investment and stockholders would tend to sell the firm's stocks.

Since the shocks firms face will have different micro- and macro-level implications depending on whether the firm is manager- or stockholder-oriented, investment decisions and financial markets performance cannot be totally independent of each other: if firms decide to increase their investment (for example, due to a change in expected profits or to respond to increasing competition), growth rates, profit rates, inflation rates and saving flows would increase, which in turn will affect financial markets. Likewise, a relatively autonomous rise in financial market optimism or a decrease in investors' risk aversion could lower the cost of capital, which could impact the investment decision made by the manager. In other words, business cycle fluctuations are the result of endogenous interactions between the real and financial sectors of the economy.

These ideas are related to the some of the tendencies discussed by the literature on financialization. ${ }^{6}$ Selected contributions include Stockhammer (2004) and Crotty (2017), who emphasize that the short-termism that has dominated firms' management during recent decades has had negative impacts on long-term investment, thus pointing out that there could be a conflict between accumulation and profitability. Orhangazi (2008) shows that financialization may have impeded real investment by decreasing available internal funds, shortening the planning horizons of the firm management and increasing uncertainty. Since firms' managers do not know how much it will cost to re-acquire the financial capital it pays back to financial markets each year, uncertainty rises, which makes some projects with attractive expected gross long-term returns too risky to undertake. Bezreh and Goldstein (2013) have tried to discuss the relevance of financial markets for the CPS mechanism, concluding that the finance-induced reversal underlies either an under-investment problem or, in sectors where coerced investment is undertaken, over-investment with financially fragile corporate balance sheets. Although Hein (2019)'s main interest consists in establishing a

the managers' view — and thus determining investment — is not well defended by Keynes (1936). Because of this, other Keynesian conceptualizations have assumed that stockholders and managers are identical agents, and that managers simply execute stockholders' decisions, so an exclusive focus on the financial roots of investment instability seems to follow naturally from the latter.

${ }^{6}$ See Lapavitsas and Mendieta-Muñoz $(2016,2018,2019)$ for a broader discussion of the main bodies of work that emphasize different aspects of financialized capitalism, and a discussion of the watershed reached in the USA following the Great Recession of 2007-2009. 
connection between stagnation tendencies and financialization, he also points out that the increase in the power of shareholders has exacerbated the channels via which internal means of finance can affect negatively firms' real investment decisions.

The present contribution is also related to some of the mainstream research that, at the theoretical level, has emphasized the existence of possible nonlinear effects derived from the interactions between business cycle fluctuations and financial conditions. Blinder (1987) constructed a model where credit rationing is the main operative mechanism via which monetary shocks can have asymmetric effects on the economy. The model developed by Bernanke and Gertler (1989) considered that balance-sheet conditions of firms can amplify fluctuations in output, and that negative shocks are likely to have larger effects than positive shocks; while the concept of financial accelerator developed by Bernanke et al. (1996) also implies that adverse shocks to the economy can be amplified by worsening credit-market conditions. Kiyotaki and Moore (1997) considered the dynamic interactions between credit constraints and asset prices, showing that these represent a powerful transmission mechanism by which the effects of shocks to technology or income distribution can generate large and persistent fluctuations in output. Azariadis and Smith (1998) studied a one-sector growth model where capital investment is credit financed and there is an adverse selection problem in credit markets, which creates an indeterminacy of equilibrium and, therefore, the economy can switch back and forth between a regime in which constraints are nonbinding and another one in which there exists credit-rationing. More recently, the models by Matsuyama (2013) and Matsuyama et al. (2016) have discussed the generation of nonlinear dynamics and asymmetric cycles in aggregate investment and borrower net worth using models of endogenous credit cycles, focusing on the idea that changing compositions of credit and of investment are responsible for creating instability and fluctuations; while Gertler et al. (2020) have constructed a model with a banking sector that also exhibits highly nonlinear contractions in economic activity associated with financial crises.

Finally, our paper is related to empirical studies that have provided evidence on the significant nonlinear interactions between the financial and real sectors of the economy. Balke (2000) and Atanasova (2003) focused on the effects associated with monetary policy shocks in the USA and the UK, respectively, finding evidence of significant asymmetric effects derived from such shocks in both economies. Specifically, monetary policy shocks during a "tight" credit regime have a larger effect on output than do shocks in the "normal" credit regime, and contractionary shocks have larger effects than expansionary shocks. Ferraresi et al. (2015) focused on how the state of credit markets affects the impact of fiscal policies in the USA, showing that fiscal multipliers are abundantly and persistently higher than one when firms face increasing financing costs and they are feebler and lower than one in the "normal" credit regime. ${ }^{7}$ Regarding countries in the Euro area, Schleer and Semmler (2015) confirmed the relevance of nonlinearities in the relationship between the financial sector and industrial production indeces and provided further evidence of amplification effects of financial sector shocks over time; while Kotz et al. (2018) investigated the effects of changes in policy interest rates on the behavior of real variables, also demonstrating evidence of regime-dependent

\footnotetext{
${ }^{7}$ Fazzari et al. (2015) also found nonlinear effects of government spending on US output, but they did not consider credit market conditions in their analysis.
} 
dynamics in aggregate output and employment. To the best of our knowledge, the only papers that have tried to consider the possible nonlinear effects of financial conditions on investment activity are panel data studies at the micro level that used sample-splitting techniques, such as Fazzari et al. (1988) and Whited (1992), who found evidence that the composition of corporate finance is an important determinant of firms' investment activity, and that small or new firms are most likely to be financially constrained and most sensitive to the availability of internal finance.

From the literature review presented in this section we take away the following points for the analysis proposed in this paper. First, a relevant way in which business cycles and its transmission mechanisms can be studied within the heterodox tradition in economics is by: (a) emphasizing the role of investment demand; and (b) considering that the sources of instability in a capitalist economy are likely the outcome of endogenous interactions between real and financial variables. Second, the great majority of mainstream literature that has considered the possible interactions between financial and real variables has: (a) assumed that financial conditions are not an important source of shocks, but rather an important nonlinear propagator of shocks; (b) shown the empirical relevance of incorporating nonlinearities - such as regime switches and asymmetric behavior - in order to study the response of macroeconomic variables to economic shocks when financial conditions are considered. Third, there are no studies that have evaluated whether: (a) investment decisions exhibit nonlinearities at the macro level; and (b) financial conditions are a relevant nonlinear source and (or) propagator of other shocks for investment decisions. The present paper contributes to these debates from a heterodox perspective by explicitly: (a) establishing an endogenous connection between financial conditions and the traditional analysis of business cycle fluctuations; and (b) providing robust empirical evidence demonstrating that the endogenous interactions between investment fluctuations and financial conditions generate nonlinear dynamics.

\section{Model specification}

It is possible to say that the traditional analysis of business cycles fluctuations at the aggregate level has assumed that the latter are the result of the interactions between investment, aggregate demand and profitability. Following a Bhaduri and Marglin (1990)-type investment function (also used by Taylor et al. (2019)), we depict such conceptualization in its linear form as follows:

$$
\frac{I}{K}=\alpha_{0}+\alpha_{1} \frac{\Pi}{K}+\alpha_{2} \frac{Y}{K},
$$

which shows that, given the parameters $\alpha_{i}, i=0,1,2$, the investment-to-capital ratio $I / K$ depends on the profit rate or profit-to-capital ratio $\Pi / K$ and the capacity utilization rate or output-to-capital ratio $Y / K$.

We use an alternative specification of the investment function presented in equation (1). Specifically, we reparameterize the latter by multiplying both sides by $K / Y$ in order to consider the investment share or the investment-to-output ratio $I / Y$ : 


$$
\begin{aligned}
\frac{I}{K} \frac{K}{Y} & =\alpha_{0} \frac{K}{Y}+\alpha_{1} \frac{\Pi}{K} \frac{K}{Y}+\alpha_{2} \frac{Y}{K} \frac{K}{Y}, \\
\frac{I}{Y} & =\alpha_{0} \frac{K}{Y}+\alpha_{1} \frac{\Pi}{Y}+\alpha_{2},
\end{aligned}
$$

where $\Pi / Y$ is the profit share of income.

We believe that the main advantage of equation (2) over (1) is that this specification includes ratios that depend less on the use of $K$. This is important because, at the empirical level, it is not clear what indicator of $K$ should be used, and because it is difficult to find official statistics for $K$ at the quarterly frequency. Given the use of Bayesian time series methods - which have greater power when a larger sample size is employed, the use of quarterly data over annual data is of utmost important since it allows us to increase considerably our sample size. ${ }^{8}$

Denoting $i_{t}=I / Y, v_{t}=Y / K$ and $\pi_{t}=\Pi / Y$, the linear investment equation represented by (2) implies the following general function $g():. i_{t}=g\left(v_{t}, \pi_{t}\right)$, so the investment share of income $i_{t}$ depends on demand pressures represented by $v_{t}$ and a distributive variable represented by $\pi_{t} \cdot{ }^{9}$ We extend this conceptualization and incorporate a variable that reflects financial conditions, $s_{t}$, in order to explicitly consider the idea that the latter matter for investment decisions:

$$
i_{t}=f\left(v_{t}, \pi_{t}, s_{t}\right) .
$$

However, since we assume that business cycle fluctuations are the result of the endogenous interactions between real and financial variables, significant challenges arise regarding the empirical estimation of equation (3). First, as mentioned by Skott (2012) and Basu et al. (2013), investment decisions involve lags, so $\pi_{t}$ could only have a lagged impact on $i_{t}$ as well as an indirect effect on $v_{t}$ since an increase in investment spending could increase $v_{t}$ with a lag (not contemporaneously), for example. Likewise, an autonomous increase in investment spending will not immediately turn into higher capital stock, so $v_{t}$ will not experience an immediate impact induced by an increase in $i_{t}$. Section 2 discussed that real and financial variables can interact endogenously, so we adopt a VAR analysis to address the endogeneity issues.

Second, we explicitly consider the possibility of nonlinear dynamics in the estimation of equation (3), so it is necessary to provide information about the general function $f($.$) . We$ adopt a threshold analysis for this purpose, which allows us to compute the dynamic behavior of all the variables in the system across different regimes; and we estimate the Threshold VAR (TVAR) using the Bayesian sampling technique described in Section 4 below.

\footnotetext{
${ }^{8}$ Although we expect that an appropriate measure of $K$ corresponds to the one employed in measures of the rate of profit, profit rates have traditionally been computed only at annual frequencies because of the uncertainty surrounding the quarterly measures of capital stock at the aggregate level.

${ }^{9}$ Note that this choice of variables is similar to the ones selected by Basu et al. (2013) in order to study the CPS. Nevertheless, in their analysis they included: (i) only an aggregate measure of $I$ instead of $i_{t}$; and (b) the unemployment rate instead of $v_{t}$. We believe that the interactions between $i_{t}, v_{t}$ and $\pi_{t}$ capture more adequately the theoretical foundations discussed in this paper.
} 
Third, on data. The investment share $i_{t}$ was calculated as nominal non-residential investment as percentage of GDP, both obtained from the National Income and Product Accounts (NIPA), Table 1.1.5. The profit share $\pi_{t}$ was computed following Baker (2016): ratio of profits after tax with inventory valuation adjustment and capital consumption adjustment to the net value added of corporate business (subtracting taxes on production and imports less subsidies), both obtained from NIPA, Table 1.1.4. Capacity utilization $v_{t}$ was approximated by $Y_{t} / Y_{t}^{*}$, where $Y_{t}^{*}$ is a measure of trend (potential) output obtained by extracting the trend component of real GDP $Y_{t}$ (NIPA, Table 1.1.6) using the Hamilton (2018) filter. ${ }^{10}$

Regarding $s_{t}$, we used the BAA spread - that is, the spread between the BAA Corporate Bond Yield and the 10-Year Treasury Constant Maturity Rate (both obtained from the Federal Reserve Economic Data, FRED) — as a proxy for financial conditions since different contributions have suggested that the latter is a good indicator related to the risk perception of investors and credit market conditions. Gertler and Lown (1999) discussed different indicators of tightness in credit markets, concluding that the high yield bond spread is a reasonable measure of tightness in credit markets since it is closely tied to monetary policy (as a sharp increase in Federal Funds rate occurs, the paper-bill spread should widen significantly). Atanasova (2003), Ferraresi et al. (2015) and Ernst et al. (2016) also used the BAA spread in their respective studies since it: (a) captures the premium for external finance; (b) is intertwined with long term investment projects; and (c) allows to capture long-term risk perception.

We limit our analysis to the period 1962Q1-2018Q3 because of the availability of the 10Year Treasury Constant Maturity Rate series, which is needed to generate the $s_{t}$ variable. Figures 1, 2, and 3 plot our measures of $i_{t}$ and $\pi_{t}, i_{t}$ and $v_{t}$, and $i_{t}$ and $s_{t}$, respectively.

\section{[INSERT FIGURE 1 ABOUT HERE]}

\section{[INSERT FIGURE 2 ABOUT HERE]}

\section{[INSERT FIGURE 3 ABOUT HERE]}

From Figure 1 it is possible to observe some preliminary evidence of $i_{t}$ responding to $\pi_{t}$ with a lag, and that this relationship might be nonlinear: a large decrease in $\pi_{t}$ in the early 1970's was followed by a small change in $i_{t}$; a decline in $\pi_{t}$ around the early 1980's was followed by a large and sharp decline in $i_{t}$; whereas a large increase in $\pi_{t}$ since the early 2000's has not been followed by large increases in $i_{t}$. Figure 2 shows that fluctuations in $i_{t}$ seem to follow variations in $v_{t}$ with a lag, but that fluctuations in $v_{t}$ were not followed by large increases in $i_{t}$ until 1970. Likewise, the sharp decline in $v_{t}$ in the 1973 recession was

\footnotetext{
${ }^{10}$ Hamilton (2018) has recently criticized the use of the Hodrick-Prescott filter-because: (i) it produces series with spurious dynamic relations; (ii) filtered values at the end of the sample are very different from those in the middle; and (iii) a statistical formalization of the problem typically produces values for the smoothing parameter vastly at odds with common practice - and has developed an alternative methodology that consists in using simple forecasts of the series to remove the cyclical component. Figure A.1 in Appendix A plots this measure of capacity utilization together with the one obtained from the Hodrick-Prescott filter. It is possible to observe that the former presents a downward deterministic trend, which is non-existent in the latter.
} 
not followed by a large increase in $i_{t}$, in contrast to the 1981 recession. Since then, the two series follow closely each other up until the 2007 crisis - where the correlation between the two variables seems to be less strong. Finally, Figure 3 presents the relationship between $i_{t}$ and $s_{t}$, showing that the latter peaks during recession years and that it seems to follow $i_{t}$ with a lag.

\section{Bayesian Threshold Vector Autoregression}

The dynamic endogenous interactions between the variables of interest presented in equation (3) can be studied by considering a linear reduced-form VAR model:

$$
Z_{t}=c+\sum_{j=1}^{J} \beta_{j} Y_{t-j}+e_{t}
$$

where $Z_{t}=\left(i_{t}, v_{t}, \pi_{t}, s_{t}\right)^{\prime}$ and $\operatorname{VAR}\left(e_{t}\right)=\Sigma$.

However, as discussed in the previous section, it is possible that the interactions between real and financial variables yield nonlinear dynamics, which cannot be captured via linear estimations. The use of TVAR models represents a flexible framework in which it is possible to incorporate regime switching, asymmetry, multiple equilibria and other types of nonlinearities. We adopt this technique, which can be represented as follows:

$$
\begin{aligned}
& Z_{t}=c_{1}+\sum_{j=1}^{J} \beta_{1} Z_{j, t-j}+e_{1, t} \\
& Z_{t}=c_{2}+\sum_{j=1}^{J} \beta_{2} Z_{j, t-j}+e_{2, t}
\end{aligned}
$$

where $\operatorname{VAR}\left(e_{1, t}\right)=\Omega_{1}$ if $T_{t} \leq Z^{*}, V A R\left(e_{2, t}\right)=\Omega_{2}$ if $T_{t}>Z^{*}, T_{t}=Z_{j, t-d}$ is the threshold variable - that is, a lag of one of the endogenous variables in the system, and $Z^{*}$ is the threshold level. ${ }^{11}$

The main advantage of the TVAR model is that it allows us to consider both the endogenous interactions between the variables in the system and the possibility of capturing two distinct regimes depending on the level taken by some variable $Z_{j, t-d}$ with respect to an unknown threshold $Z^{*}$, so the variables may respond differently to shocks in the system above and below that estimated threshold.

We adopt Bayesian simulation methods in our estimation because of the following advantages: (i) TVAR models involve a large number of parameters, so we face the risk that innovation accounting methods (impulse response analyses and variance decompositions) become imprecise if a classical approach is used, while Bayesian methods which utilize prior information in the estimation process offer the possibility of computing more precise estimates (Blake and Mumtaz , 2017); and (ii) Bayesian TVAR (BTVAR)

\footnotetext{
${ }^{11}$ Notice that if $Z^{*}$ and $d$ are known then the TVAR is simply two VAR models defined over the respective samples using $T_{t} \leq Z^{*}$ and $T_{t}>Z^{*}$.
} 
models avoid sophisticated analytical and numerical multiple integration, thus providing an estimate of the threshold value directly without resorting to a subjective choice from various scatterplots (Chen and Lee, 1995).

Finally, we mention two important elements regarding our empirical implementation. ${ }^{12}$ First, following the extant literature (Sims and Zha , 1998; Bańbura et al. , 2010; Alessandri and Mumtaz , 2017; Blake and Mumtaz , 2017), we use dummy variables to implement natural conjugate priors as well as prior beliefs regarding the existence of a common stochastic trend and a unit root in our system. Specifically, the natural conjugate prior incorporates the information that the system's covariance matrix should be a positive definite matrix and accelerates the sampling algorithm considerably - in contrast, for example, to other priors that can be incorporated via the covariance matrix in the VAR model. The sum of coefficients or unit root prior incorporates the information that some of the coefficients on lags of the variables in our system sum to 1 , that is, they have a unit root; and the common stochastic trend prior incorporates the information that the variables in our system may also share stochastic trends, which can be important to control for possible long-run dynamics in our analysis of business cycles.

Second, the Gibbs sampling algorithm can be used to obtain the desired marginal posterior densities of the threshold value and other parameters since it provides an efficient way to obtain point estimates and to characterize the uncertainty around the latter. Nevertheless, such an algorithm relies on the availability of conditional distributions to be operational and, in a BTVAR model, the conditional distribution of different parameter blocks is unavailable (Blake and Mumtaz , 2017). This means that we need a more general method that enables us to approximate the posterior distributions, so we implemented a Gibbs sampling algorithm augmented with a Metropolis Hastings step in our estimations.

\section{Results}

Following the literature that has explicitly studied the possible nonlinear interactions between the financial and real sectors of the economy, we selected the spread variable $s_{t}$ as that endogenous variable which determines the threshold effect. Specifically, given that the actual $s_{t}$ series has high variability - which implies a frequency of regime switching that is implausible, we set the threshold variable to be a moving average of order $6(\mathrm{MA}(6))$ of past spread variables in order to have a consistent in level of persistence in these series (see also Balke (2000); Atanasova (2003); Ferraresi et al. (2015)). ${ }^{13}$ Our preferred specification uses BTVAR estimations with 4 lags in order to incorporate one year of data analysis; and uses the delay parameter $d=1$ in order to incorporate the most immediate values of our indicator of financial conditions. ${ }^{14}$

\footnotetext{
${ }^{12}$ Appendix B offers a formal discussion of the econometric techniques used to estimate the BTVAR, which complements this summary.

${ }^{13}$ Nevertheless, note that the credit variable enters the BTVAR directly in its original form (as an element of $Z_{t}$ ), rather than as a moving average.

${ }^{14}$ As a robustness check, we also performed the estimations considering a $\mathrm{MA}(2)$ of the $s_{t}$ series and changed the delay parameter to $d=2$, finding consistent results with the ones presented in this section and in the appendices. These results are available on request.
} 
Since our main interest consists in studying only the short-run dynamic interactions between the variables, we used Cholesky decompositions to solve the identification problem. We considered two plausibly relevant ordering of variables to identify the system in order to generate meaningful impulse response functions (IRFs) and to study the transmission mechanisms of business cycles. First, $s_{t} \rightarrow v_{t} \rightarrow \pi_{t} \rightarrow i_{t}$, which implies the following contemporaneous restrictions: (i) a shock in $s_{t}$ can affect contemporaneously $v_{t}, \pi_{t}$ and $i_{t}$, but not vice versa; (ii) a shock in $v_{t}$ affects contemporaneously only $\pi_{t}$ and $i_{t}$; (iii) a shock to $\pi_{t}$ affects only $i_{t}$ within the same period; and (iv) $i_{t}$ does not affect any of the variables in the system contemporaneously (it only does it with a lag). Thus, this ordering of variables in the model assumes that the transmission of shocks in the short-run begins with changes in $s_{t}$.

Figures 4 through 7 below report the IRFs derived from this identification strategy. ${ }^{15}$ The estimated threshold for the MA(6) of $s_{t}$ is approximately 2.46 (percentage points), so we observe different responses of the variables to shocks in the system below and above this value. The first regime can be interpreted as a regime depicting loose financial conditions; whereas the latter as a regime associated with tighter financial conditions. ${ }^{16}$

\section{[INSERT FIGURE 4 ABOUT HERE]}

\section{[INSERT FIGURE 5 ABOUT HERE]}

\section{[INSERT FIGURE 6 ABOUT HERE]}

\section{[INSERT FIGURE 7 ABOUT HERE]}

Figure 4 displays the results for a one standard deviation shock to $s_{t}$. There is a clear difference in the response of the variables across the two regimes as we observe more persistent effects associated with the $s_{t}$ shock when the economy is below the estimated threshold level - that is, when the economy is in the loose financial conditions regime. We observe an initial decline in $v_{t}$ in both regimes followed by an increase that is statistically significant only in the first regime, so $v_{t}$ takes longer to stabilize in the first regime compared with the second one. $\pi_{t}$ responds positively to $s_{t}$, and its response in Regime 1 is also more persistent; while $i_{t}$ responds negatively to the $s_{t}$ shock and its response is also statistically significant for a longer period in Regime 1 relative to Regime 2 .

The responses of the variables to a shock in the demand variable $v_{t}$ are presented in Figure 5. It is possible to observe that shocks in $v_{t}$ do not generate statistically significant responses of $s_{t}$ and $\pi_{t}$, and only a marginally statistically significant response of $i_{t}$ over few quarters in Regime 2-that is, when the economy is in the tight financial conditions regime; while there are statistically significant positive (negative) responses of $\pi_{t}$ and $i_{t}\left(s_{t}\right)$ in Regime 1.

\footnotetext{
${ }^{15}$ We also estimated a linear Bayesian VAR (BVAR), which assumes the existence of only one regime (no threshold effects). These results are presented in Appendix C. Since one of our main interests consists in determining whether threshold effects are important, the results obtained from such a linear estimation technique are less relevant for the purposes of the current paper.

${ }^{16}$ Appendix D reports the traceplots corresponding to the estimated parameters and the variancecovariances matrices of the BTVAR models as evidence of convergence of the Bayesian sampling method.
} 
Figure 6 plots the responses to a one standard deviation shock to $\pi_{t}$. In Regime 1 , there is a (short-lived) statistically significant negative (positive) response of $s_{t}\left(v_{t}\right)$. The response of $i_{t}$ is interesting as there is an initial marginal negative response to the shock in $\pi_{t}$ that becomes positive approximately from the seven-quarter ahead onward. In Regime 2 , a shock in $\pi_{t}$ does not generate a statistically significant response of $s_{t} ; v_{t}$ responds negatively and persistently (from the eight-quarter ahead onward); and there is only an initial negative marginally statistically significant response of $i_{t}$. This finding implies that, in the loose financial conditions regime, a redistribution of income toward profits is effective in increasing investment (for the majority of quarters ahead); but the situation changes drastically when the economy in the tight financial conditions regime as there is no positive effect of $\pi_{t}$ on $i_{t}$.

With regards to a one standard deviation shock in $i_{t}$, shown in Figure 7 , we also find more persistent responses of the variables in Regime 1 relative to Regime 2. The responses of $s_{t}, v_{t}$ and $\pi_{t}$ in Regime 2 are all statistically non-significant; whereas there is a statistically significant response of these three variables to a shock in $i_{t}$ in Regime 1 , the most persistent being the positive response of $s_{t}$.

The second Cholesky ordering of variables used to identify the system was $v_{t} \rightarrow s_{t} \rightarrow \pi_{t}$ $\rightarrow i_{t}$. This conceptualization implies that the transmission of shocks in the short-run begins with changes in the variable that captures aggregate demand pressures, $v_{t}$. Specifically, it assumes that, within the same period, the following restrictions hold: (i) shocks in $v_{t}$ affect contemporaneously the other three variables, but not vice versa; (ii) shocks to $s_{t}$ can effect contemporaneously only $\pi_{t}$ and $i_{t}$; (iii) shocks in $\pi_{t}$ affect contemporaneously only $i_{t}$; and (iv) shocks to $i_{t}$ do not effect $v_{t}, s_{t}$ or $\pi_{t}$ within the same quarter (only with a lag).

Figures 8, 9, 10 and 11 present the results obtained from a one standard deviation shock to $v_{t}, s_{t}, \pi_{t}$ and $i_{t}$, respectively, following this alternative identification strategy.

\section{[INSERT FIGURE 8 ABOUT HERE] \\ [INSERT FIGURE 9 ABOUT HERE] \\ [INSERT FIGURE 10 ABOUT HERE] \\ [INSERT FIGURE 11 ABOUT HERE]}

The results presented above corroborate those obtained when the first identification strategy was deployed. The most important finding is that the responses of all variables to shocks are more persistent and statistically significant over a longer period in Regime 1, the only exception being the persistent negative response of $v_{t}$ to a shock in $\pi_{t}$ in Regime 2. Therefore, shocks affecting the economy during a loose financial conditions regime-Regime 1-generate more persistent responses in the variables compared with shocks affecting the economy during tighter financial conditions - Regime $2 .{ }^{17}$

\footnotetext{
${ }^{17}$ Appendix E presents the estimation results considering only the neoliberal period, 1980Q1-2018Q3, using the same two Cholesky orderings. The results corroborate the main finding for the period 1962Q1-2018Q3namely, the response of the majority of variables in Regime 1 (loose financial conditions) is more persistent over a longer period compared with Regime 2 (tight financial conditions). However, there are also important differences that are necessary to mention: (i) shocks in $v_{t}$ do not generate statistically significant effects on $\pi_{t}$ in either regime; (ii) the positive response of $\pi_{t}$ to shocks in $s_{t}$ in Regime 2 is greater than in Regime 1 as well as the positive response of $i_{t}$ to shocks in $\pi_{t}$; (iii) neither $v_{t}$ nor $\pi_{t}$ seem to respond significantly to shocks in $i_{t}$. A comprehensive examination of these differences could offer important elements that explain the structural changes in US business cycle fluctuations. We leave these issues for future research.
} 


\section{Conclusions}

This paper has presented a conceptualization of business cycle fluctuations in which the role of financial conditions is explicitly incorporated. Our contribution builds on previous literature that has emphasized: (i) the importance of investment demand in driving economic fluctuations; (ii) that the sources of macroeconomic instability are likely an endogenous result of the interactions between real and financial sectors of the economy; (iii) that deteriorating financial conditions can act as a major factor depressing real economic activity; and (iv) the importance of nonlinear dynamics when traditional business cycle fluctuations and financial conditions are considered.

We posit that business cycles and its transmission mechanisms can be adequately captured by the dynamic interactions between investment decisions, profit levels, aggregate demand levels, and financial conditions; and considered that the latter are both an important source of instability and a possible nonlinear propagator of other sources of instability in the economy. We use a Threshold Vector Autoregression model for the US economy, which allows us to capture both the endogenous interactions between the variables of interest and to incorporate nonlinear responses to endogenous shocks by capturing two distinct regimes associated with a threshold value defined by an indicator of financial conditions. Using a Bayesian sampling algorithm - which enables us to use prior information in the estimation, to compute more precise estimates, and to minimize the subjectivity associated with the estimation of the threshold value - we find evidence of significant differences regarding the persistence of shocks when the economy is in different regimes of financial stress. Specifically, when the state of the economy corresponds to loose financial conditions, shocks in the economic system generate more persistent responses (statistically significant over a longer period) of all endogenous variables relative to the situation in which the state of the economy corresponds to that of tight financial conditions. This result is robust to alternative conceptualizations of the transmission of shocks in the short-run - assuming that either a variable that measures financial tightness (such as the interest rate spread) or a variable capturing demand pressures (such as capacity utilization) is the first one that is affected.

Our research raises questions about the underlying nature of short-run business cycle fluctuations, the relevance of financial conditions for such analyses, and the importance of incorporating nonlinear dynamics in order to provide more realistic characterizations of its propagation mechanisms. Future theoretical research may try to explicitly incorporate the determination of multiple equilibria considering both real and financial sectors using, for example, alternative microfoundations; while future empirical research may try to identify the most relevant type of nonlinearity that dominates economic fluctuations when financial (or credit) conditions are incorporated. We believe that this is relevant work that remains to be done. 


\section{References}

Alessandri, P. and Mumtaz, H. (2017). "Financial conditions and density forecasts for US output and inflation". Review of Economic Dynamics, 24: 66-78.

Atanasova, C. (2003). "Credit market imperfections and business cycle dynamics: a nonlinear approach". Studies in Nonlinear Dynamics and Econometrics, 7(4): 1-22.

Azariadis, C. and Smith, B. (1998). "Financial intermediation and regime switching in business cycles". American Economic Review, 88(3): 516-536.

Baker, D. (2016). "The upward redistribution of income: are rents the story?". Review of Radical Political Economics, 48(4): 529-543.

Bakir, E. and Campbell, A. (2006). "The effect of neoliberalism on the fall in the rate of profit in business cycles". Review of Radical Political Economics, 38(3): 365-373.

Balke, N. (2000). "Credit and economic activity: credit regimes and nonlinear propagation of shocks". Review of Economics and Statistics, 82(2): 344-349.

Bańbura, M., Giannone, D. and Reichlin, L. (2010). "Large Bayesian vector auto regressions". Journal of Applied Econometrics, 25(1): 71-92.

Bhaduri, A. and Marglin, S. (1990). "Unemployment and the real wage: the economic basis for contesting political ideologies". Cambridge Journal of Economics, 14(4): 375-393.

Barrales, J. and von Arnim, R. (2017). "Longer-run distributive cycles: wavelet decompositions for the US, 1948-2011". Review of Keynesian Economics, 5(2): 196-217.

Basu, D., Chen, Y. and Oh, J. (2013). "Class struggle and economic fluctuations: VAR analysis of the post-war US economy". International Review of Applied Economics, 27(5): 575-596.

Bernanke, B. and Gertler, M. (1989). "Agency costs, net worth, and business fluctuations". American Economic Review, 79(1): 14-31.

Bernanke, B., Gertler, M. and Gilchrist, S. (1996). "The financial accelerator and the flight to quality". Review of Economics and Statistics, 78(1): 1-15.

Bezreh, M. and Goldstein, J. (2013). "Real and financial determinants of the profit share: the financial profit squeeze". Political Economy Research Institute (PERI), University of Massachusetts Working Paper, No. 307.

Blake and Mumtaz (2017). Applied Bayesian Econometrics for Central Bankers. London: Bank of England, Centre for Central Banking Studies.

Blinder, A. (1987). "Credit rationing and effective supply failures". Economic Journal, 97(386): 327-352.

Blanchard, O. (2017). Macroeconomics. Boston: Pearson. 
Boddy, R. and Crotty, J. (1975). "Class conflict and macro-policy: the political business cycle". Review of Radical Political Economics, 7(1): 1-19.

Chen, C. and Lee, J. (1995). "Bayesian inference of threshold autoregressive models". Journal of Time Series Analysis, 16(5): 483-492.

Crotty, J. (1985). "The centrality of money, credit, and financial intermediation in Marx's crisis theory: an interpretation of Marx's methodology". In Resnick, S. and Wolff, R. (eds.) Rethinking Marxism: Essays for Harry Magdoff and Paul Sweezy. New York City: Autonomedia, pp. 45-81.

Crotty, J. (1990). "Owner-manager conflict and financial theories of investment instability: a critical assessment of Keynes, Tobin, and Minsky". Journal of Post Keynesian Economics, 12(4): 519-542.

Crotty, J. (2017). "The neoliberal paradox: the impact of destructive product market competition and "modern" financial markets on nonfinancial corporation performance in the neoliberal era". In Crotty, J. Capitalism, Macroeconomics and Reality: Understanding Globalization, Financialization, Competition and Crisis. Cheltenham: Edward Elgar, pp. $272-304$.

Epstein, G. (1991). "Profit squeeze, rentier squeeze and macroeconomic policy under fixed and flexible exchange rates". Economies et Societies, 25(11-12): 219-257.

Ernst, E., Mittnik, S and Semmler, W. (2016). "Interaction of labor and credit market frictions: a theoretical and empirical analysis". Economic Notes, 45(3): 393-422.

Fazzari, S., Hubbard, R., Petersen, B., Blinder, A. and Poterba, J. (1988). "Financing constraints and corporate investment". Brookings Papers on Economic Activity, 1: 141206.

Fazzari, S., Morley, J. and Panovska, I. (2015). "State-dependent effects of fiscal policy". Studies in Nonlinear Dynamics and Econometrics, 19(3): 285-315.

Ferraresi, T., Roventini, A. and Fagiolo, G. (2015). "Fiscal policies and credit regimes: a TVAR approach". Journal of Applied Econometrics, 30(7): 1047-1072.

Gertler, M. and Lown C. (1999). "The information in the high-yield bond spread for the business cycle: evidence and some implications". Oxford Review of Economic Policy, 15(3): 132-150.

Gertler, M., Kiyotaki, N. and Prestipino, A. (2020). "A macroeconomic model with financial panics". Review of Economic Studies, 87(1): 240-288.

Goodwin, R. (1967). "A growth cycle". In Feinstein, C. (Ed.) Socialism, Capitalism and Economic Growth: Essays Presented to Maurice Dobb. Cambridge: Cambridge University Press, pp. 54-58. 
Goldstein, J. (1985). "The cyclical profit squeeze: a Marxian microfoundation". Review of Radical Political Economics, 17(1-2): 103-128.

Goldstein, J. (1999a). "Predator-prey models estimates of the cyclical profit squeeze". Metroeconomica, 50(2): 139-173.

Goldstein, J. (1999b). "The simple analytics and empirics of the Cyclical Profit Squeeze and cyclical underconsumption theories: Clearing the air". Review of Radical Political Economics, 31(2): 74-88.

Goldstein, J. (2002). "The profit squeeze is supported by the PW cycle indicator.". Review of Radical Political Economics, 34(1): 75-77.

Hamilton, J. (2018). "Why you should never use the Hodrick-Prescott filter". Review of Economics and Statistics, 100(5): 831-843.

Hein, E. (2019). "Financialisation and tendencies towards stagnation: the role of macroeconomic regime changes in the course of and after the financial and economic crisis 2007-09". Cambridge Journal of Economics, 43(4): 975-999.

Kalecki, M. (1971). Selected Essays on the Dynamics of the Capitalist Economy, 1933-1970. Cambridge: Cambridge University Press.

Keynes, J. (1936)[2007]. "The General Theory of Employment, Interest and Money". London: Palgrave Macmillan.

Kiefer, D. and Rada, C. (2015). "Profit maximizing goes global: the race to the bottom". Cambridge Journal of Economics, 39(5): 1333-1350.

Kiyotaki, N. and Moore, J. (1997). "Credit cycles". Journal of Political Economy, 105(2): 211-248.

Kotz, H., Semmler, W. and Tahri, I. (2018). "Financial fragmentation and the monetary transmission mechanism in the euro area: a smooth transition VAR approach". Studies in Nonlinear Dynamics and Econometrics, 22(5): 1-19.

Lapavitsas, C. and Mendieta-Muñoz, I. (2016). "The profits of financialization". Monthly Review, 68(3): 49-62.

Lapavitsas, C. and Mendieta-Muñoz, I. (2018). "Financialization at a watershed in the USA". Competition and Change, 22(5): 488-508.

Lapavitsas, C. and Mendieta-Muñoz, I. (2019). "The historic rise of financial profits in the US economy". Journal of Post Keynesian Economics, 42(3): 443-468.

Marglin, S. and Bhaduri, A. (1992). "Profit squeeze and Keynesian theory". In Marglin, S. and Schor, J. (Eds.) The Golden Age of Capitalism: Reinterpreting the Postwar Experience. Oxford: Oxford University Press, pp. 153-186.

World Institute of Development Economics Research Working Paper, No. 39. 
Marx, K. (1867)[1993]. "Capital: A Critique of Political Economy, Volume I". London: Penguin Classics.

Marx, K. (1894)[1993]. "Capital: A Critique of Political Economy, Volume III". London: Penguin Classics.

Matsuyama, K. (2013). "The Good, the Bad, and the Ugly: An inquiry into the causes and nature of credit cycles". Theoretical Economics, 8: 623-651.

Matsuyama, K., Sushko, I. and Gardini, L. (2016). "Revisiting the model of credit cycles with Good and Bad projects". Journal of Economic Theory, 163: 525-556.

Michl, T. (1988a). "The two-stage decline in U.S. nonfinancial corporate profitability, 194886". Review of Radical Political Economics, 20(4): 1-22.

Minsky, H. (1986)[2008]. Stabilizing an Unstable Economy. New York City: McGraw-Hill.

Orhangazi, Ö. (2019). "Financialisation and capital accumulation in the non-financial corporate sector: a theoretical and empirical investigation on the US economy: 19732003". Cambridge Journal of Economics, 32(6): 863-886.

Rada, C. and Kiefer, D. (2016). "Distribution-utilization interactions: a race-to-the-bottom among OECD countries". Metroeconomica, 67(2): 477-498.

Robertson, J. and Tallman, E. (1999). "Vector autoregressions: forecasting and reality". Federal Reserve Bank of Atlanta Economic Review, 84(1): 4-18.

Schleer, F. and Semmler, W. (2015). "Financial sector and output dynamics in the euroarea: non-linearities reconsidered". Journal of Macroeconomics, 46(C): 235-263.

Sherman, H. (1972). Radical Political Economy. New York City: Basic Books.

Sherman, H. (1997). Theories of cyclical profit squeeze. Review of Radical Political Economics, 29(1): 9-17.

Sims, C. and Zha, T. (1998). "Bayesian methods for dynamic multivariate models". International Economic Review, 39(4): 949-968.

Skott, P. (2012). "Theoretical and empirical shortcomings of the Kaleckian investment function". Metroeconomica, 63(1): 109-138.

Stockhammer, E. (2004). "Financialisation and the slowdown of accumulation". Cambridge Journal of Economics, 28(5): 719-741.

Taylor, L., Foley, D. and Rezai, A. (2019). "Demand drives growth all the way: Goodwin, Kaldor, Pasinetti and the steady state". Cambridge Journal of Economics, 43(5): $1333-1352$.

Von Arnim, R. and Barrales (2015). "Demand-driven Goodwin cycles with Kaldorian and Kaleckian features". Review of Keynesian Economics, 3(3): 351-373. 
Weisskopf, T. (1992). "A comparative analysis of profitability trends in the advanced capitalist economies". In Moseley, F. and Wolff, E. (Eds.) International Perspectives on Profitability and Accumulation. Cheltenham: Edward Elgar, pp. 13-14.

Whited, T. (1992). "Debt, liquidity constraints, and corporate investment: evidence from panel data". Journal of Finance, 47(4): 1425-1460. 


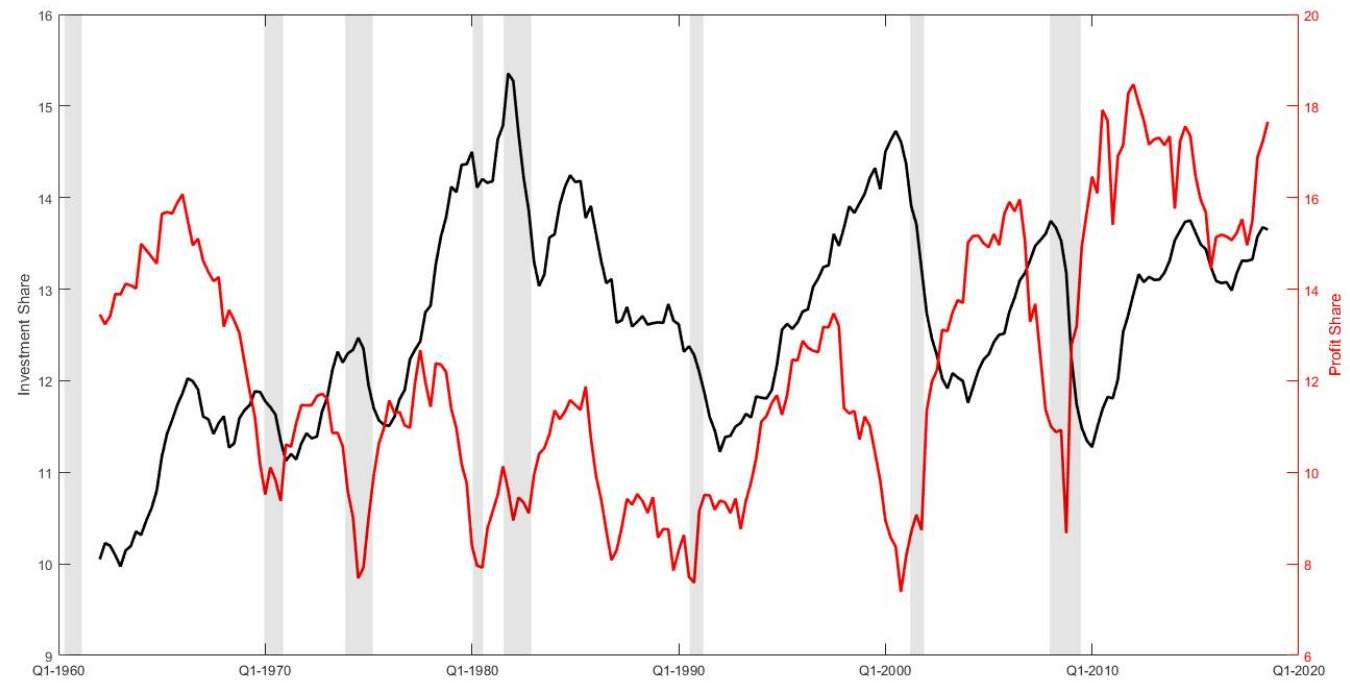

Figure 1: USA, 1962Q1-2018Q3: Investment share and profit share (percentages). Black and red lines correspond to the investment share (left axis) and the profit share (right axis), respectively. Shaded areas indicate NBER recession dates.

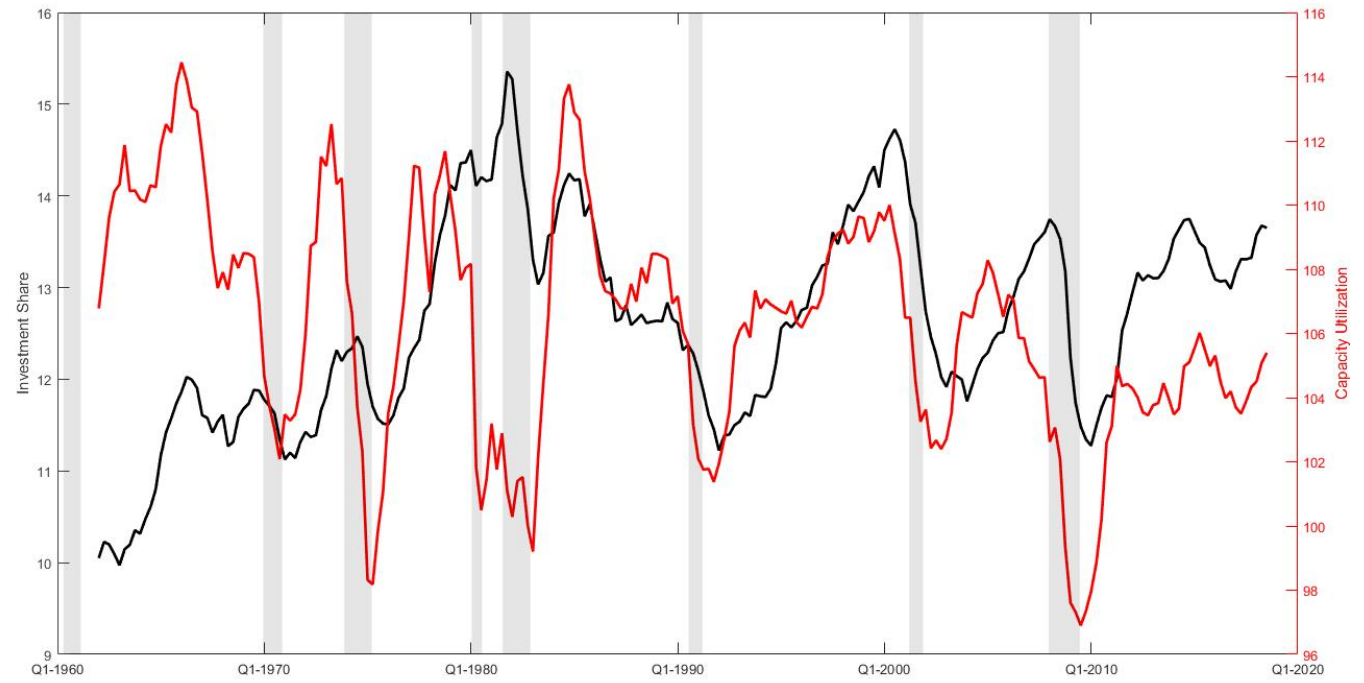

Figure 2: USA, 1962Q1-2018Q3: Investment share and capacity utilization (percentages). Black and red lines correspond to the investment share (left axis) and capacity utilization (right axis), respectively. Shaded areas indicate NBER recession dates. 


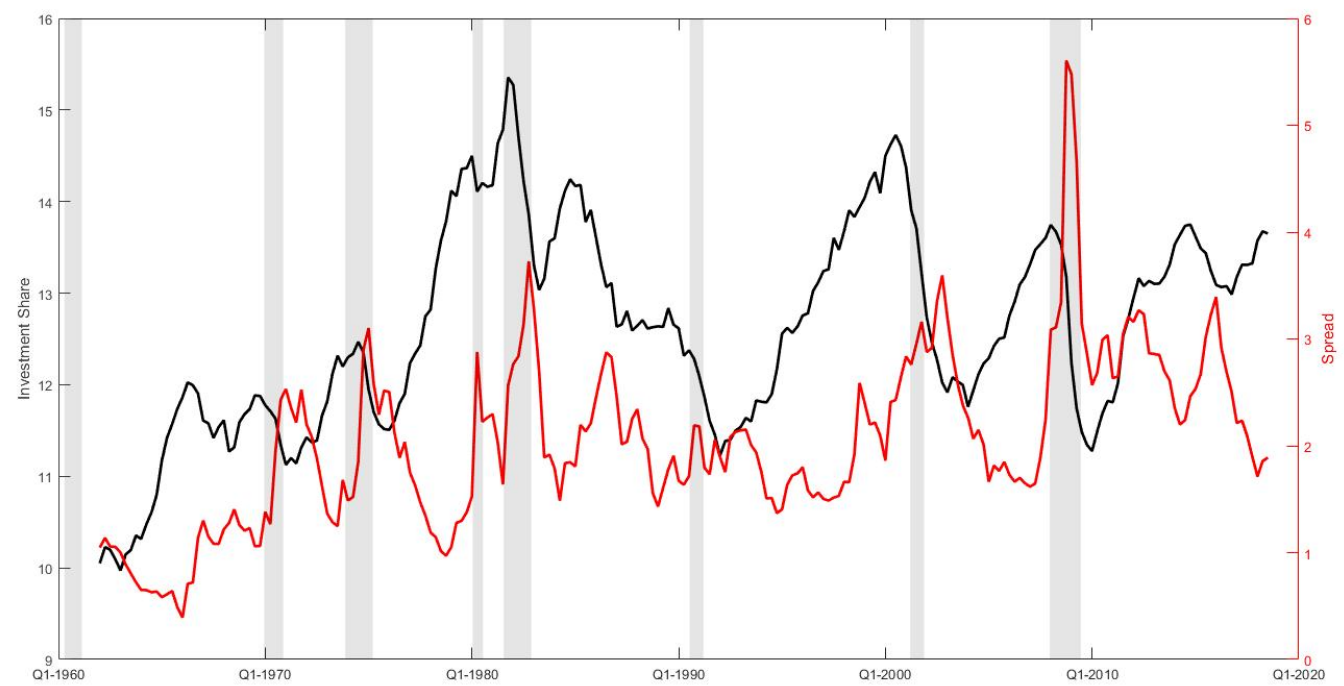

Figure 3: USA, 1962Q1-2018Q3: Investment share (percentage) and credit spread (percentage points). Black and red lines correspond to the investment share (left axis) and the credit spread (right axis), respectively. Shaded areas indicate NBER recession dates.
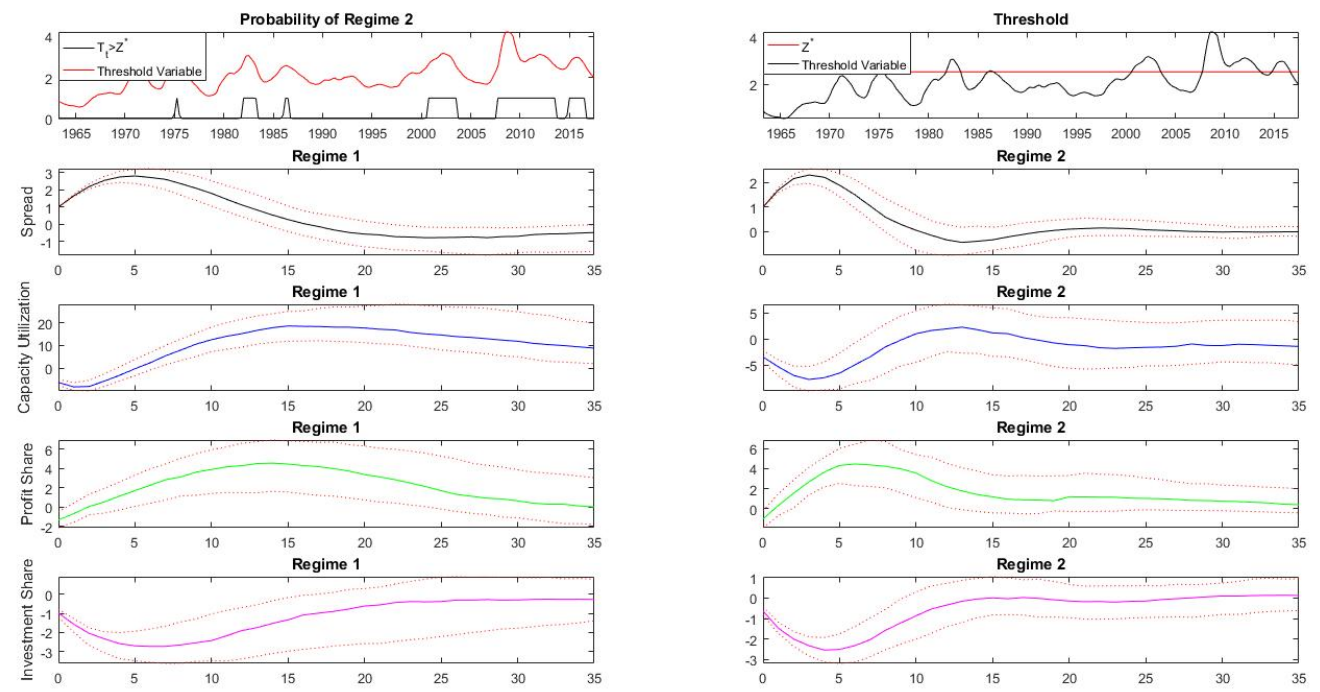

Figure 4: USA, 1962Q1-2018Q3. Impulse-response functions obtained from a one standard deviation shock to spread $s_{t}$. The ordering of the variables in the BTVAR is $s_{t} \rightarrow v_{t} \rightarrow$ $\pi_{t} \rightarrow i_{t}$. The horizontal axis shows quarters ahead in all figures. Red dotted lines correspond to the $68 \%$ confidence intervals. The estimated threshold for the MA(6) of $s_{t}$ is approximately 2.46. Regimes 1 and 2 represent the regimes associated with loose and tight financial conditions, respectively. 

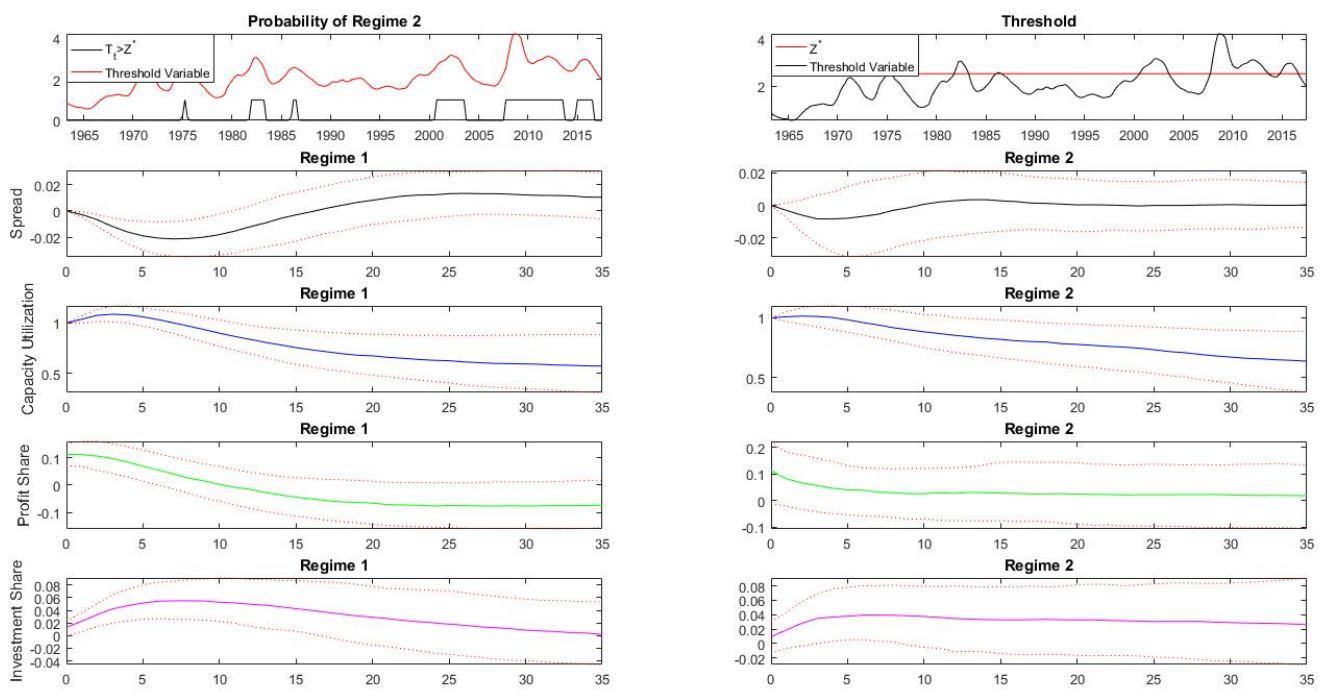

Figure 5: USA, 1962Q1-2018Q3. Impulse-response functions obtained from a one standard deviation shock to capacity utilization $v_{t}$. The ordering of the variables in the BTVAR is $s_{t} \rightarrow v_{t} \rightarrow \pi_{t} \rightarrow i_{t}$. The horizontal axis shows quarters ahead in all figures. Red dotted lines correspond to the $68 \%$ confidence intervals. The estimated threshold for the MA(6) of $s_{t}$ is approximately

2.46. Regimes 1 and 2 represent the regimes associated with loose and tight financial conditions, respectively.
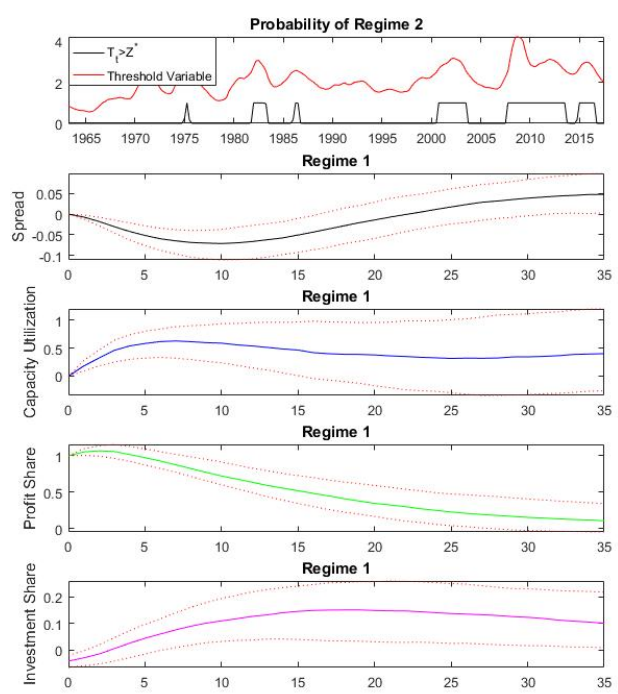
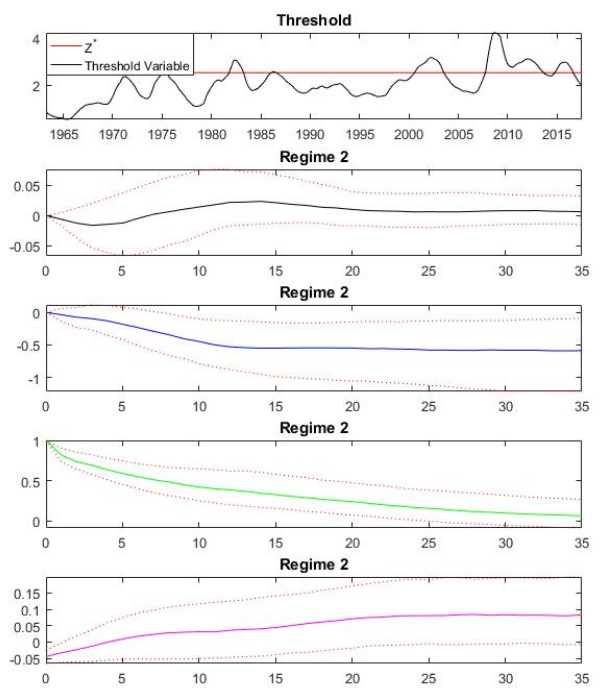

Figure 6: USA, 1962Q1-2018Q3. Impulse-response functions obtained from a one standard deviation shock to profit share of income $\pi_{t}$. The ordering of the variables in the BTVAR is $s_{t} \rightarrow v_{t} \rightarrow \pi_{t} \rightarrow i_{t}$. The horizontal axis shows quarters ahead in all figures. Red dotted lines correspond to the $68 \%$ confidence intervals. The estimated threshold for the MA(6) of $s_{t}$ is approximately

2.46. Regimes 1 and 2 represent the regimes associated with loose and tight financial conditions, respectively. 

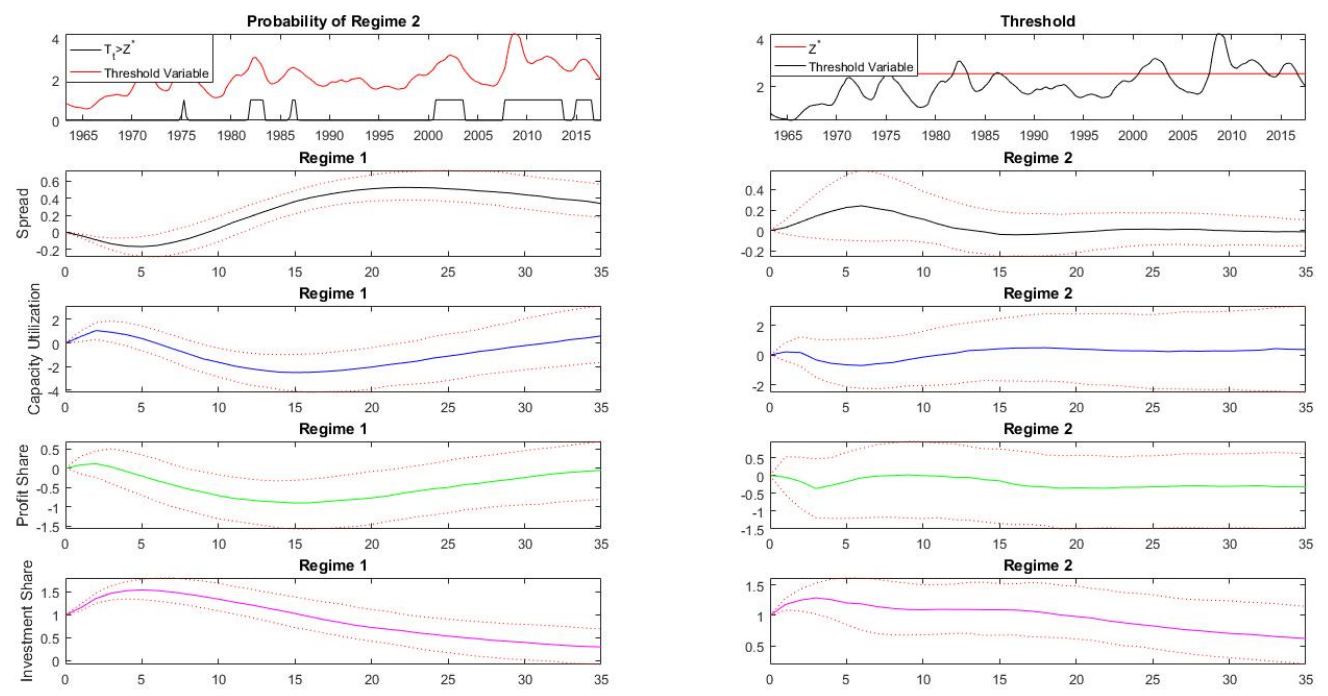

Figure 7: USA, 1962Q1-2018Q3. Impulse-response functions obtained from a one standard deviation shock to investment share of income $i_{t}$. The ordering of the variables in the BTVAR is $s_{t} \rightarrow v_{t} \rightarrow \pi_{t} \rightarrow i_{t}$. The horizontal axis shows quarters ahead in all figures. Red dotted

lines correspond to the $68 \%$ confidence intervals. The estimated threshold for the MA(6) of $s_{t}$ is approximately 2.46. Regimes 1 and 2 represent the regimes associated with loose and tight financial conditions, respectively.
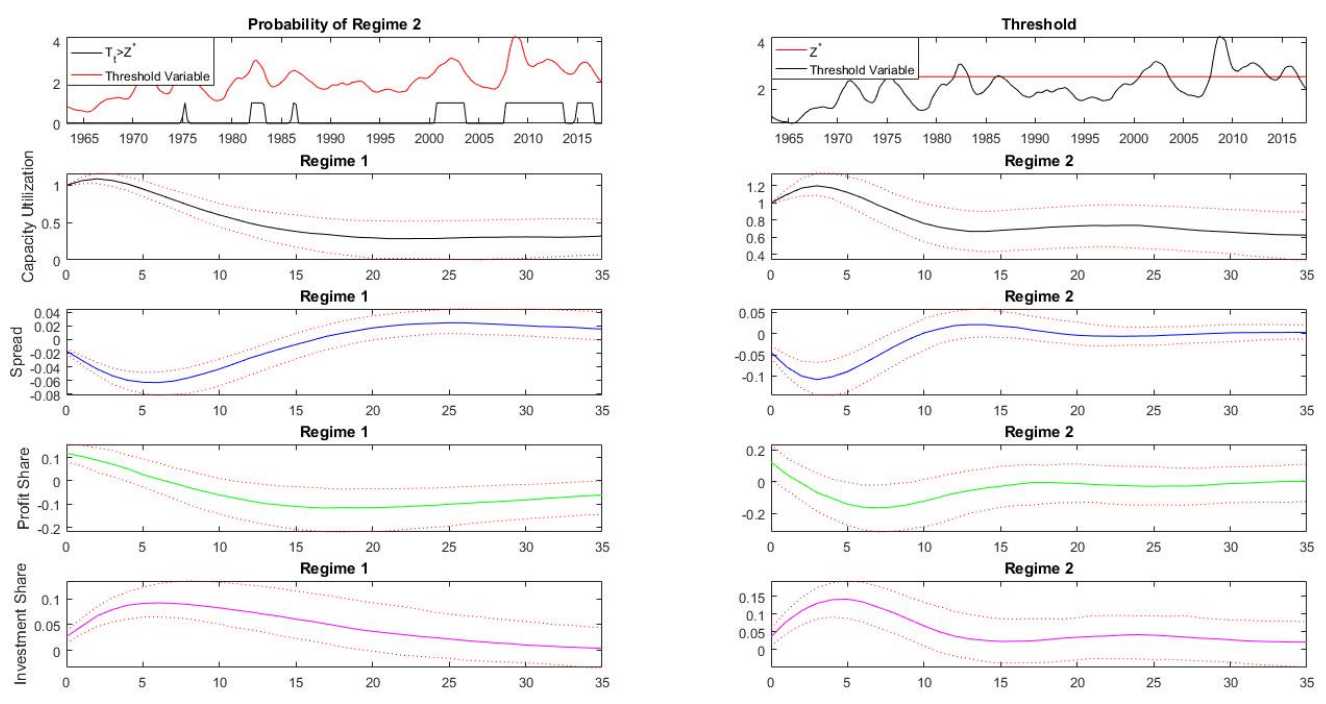

Figure 8: USA, 1962Q1-2018Q3. Impulse-response functions obtained from a one standard deviation shock to capacity utilization $v_{t}$. The ordering of the variables in the BTVAR is $v_{t} \rightarrow s_{t} \rightarrow \pi_{t} \rightarrow i_{t}$. The horizontal axis shows quarters ahead in all figures. Red dotted lines correspond to the $68 \%$ confidence intervals. The estimated threshold for the MA(6) of $s_{t}$ is approximately

2.46. Regimes 1 and 2 represent the regimes associated with loose and tight financial conditions, respectively. 

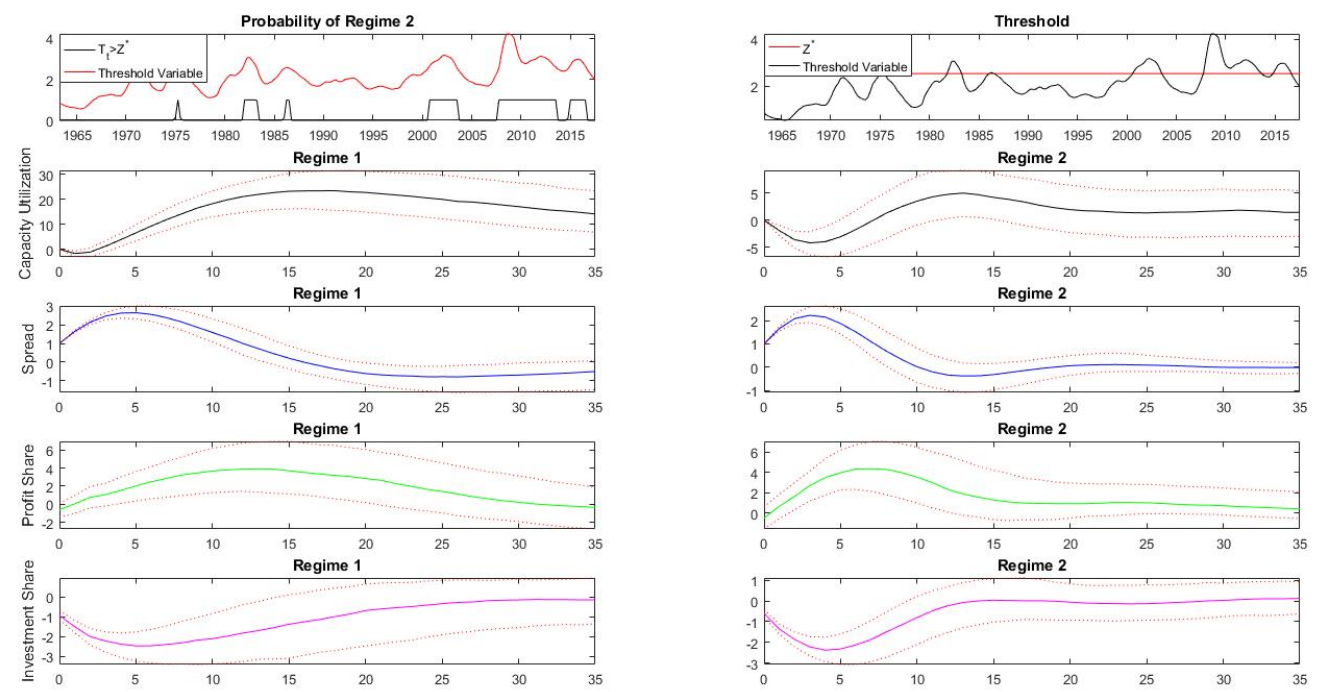

Figure 9: USA, 1962Q1-2018Q3. Impulse-response functions obtained from a one standard deviation shock to spread $s_{t}$. The ordering of the variables in the BTVAR is $v_{t} \rightarrow s_{t} \rightarrow$ $\pi_{t} \rightarrow i_{t}$. The horizontal axis shows quarters ahead in all figures. Red dotted lines correspond to the $68 \%$ confidence intervals. The estimated threshold for the MA(6) of $s_{t}$ is approximately 2.46 . Regimes 1 and 2 represent the regimes associated with loose and tight financial conditions, respectively.
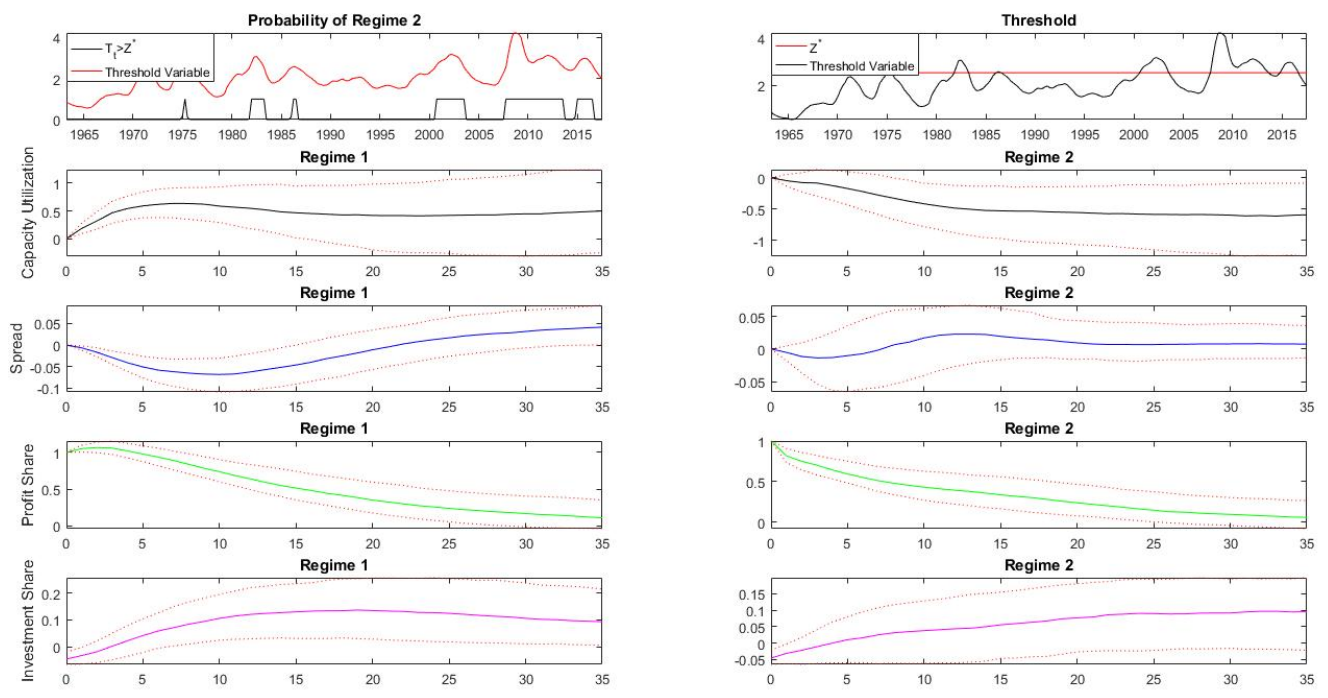

Figure 10: USA, 1962Q1-2018Q3. Impulse-response functions obtained from a one standard deviation shock to profit share of income $\pi_{t}$. The ordering of the variables in the BTVAR is $v_{t} \rightarrow s_{t} \rightarrow \pi_{t} \rightarrow i_{t}$. The horizontal axis shows quarters ahead in all figures. Red dotted lines correspond to the $68 \%$ confidence intervals. The estimated threshold for the MA(6) of $s_{t}$ is approximately

2.46. Regimes 1 and 2 represent the regimes associated with loose and tight financial conditions, respectively. 

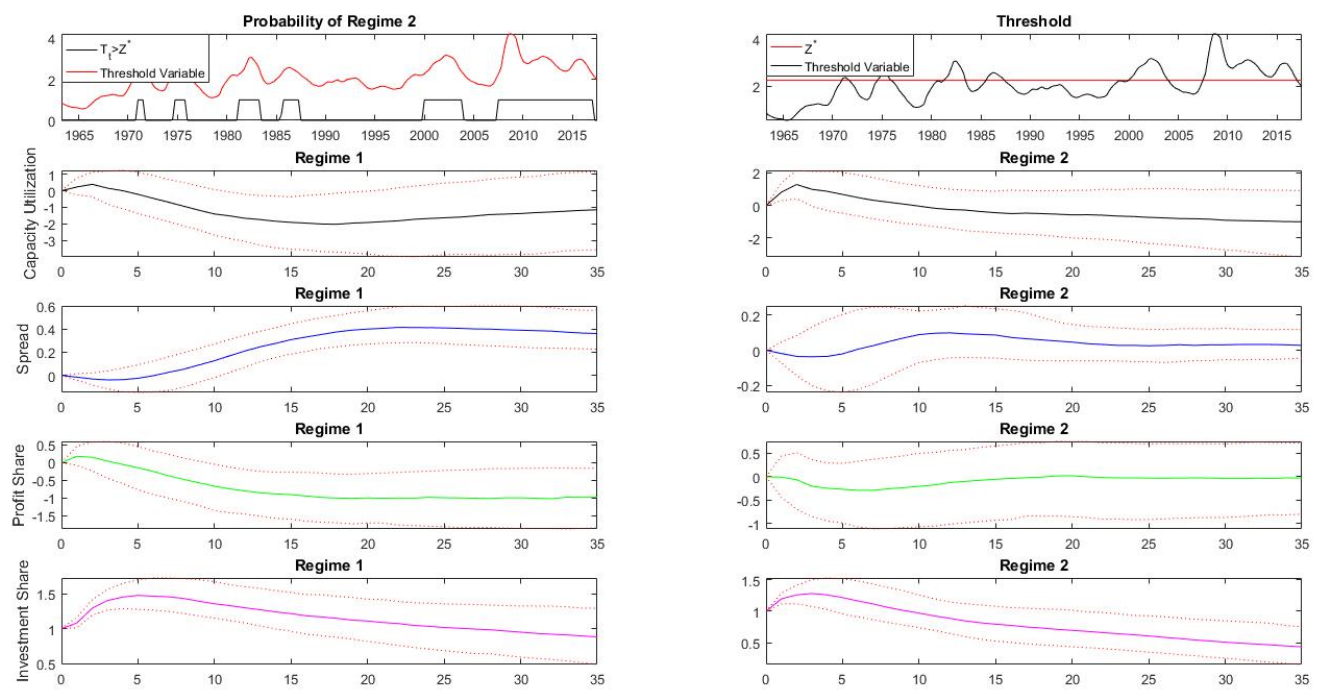

Figure 11: USA, 1962Q1-2018Q3. Impulse-response functions obtained from a one standard deviation shock to investment share of income $i_{t}$. The ordering of the variables in the BTVAR is $v_{t} \rightarrow s_{t} \rightarrow \pi_{t} \rightarrow i_{t}$. The horizontal axis shows quarters ahead in all figures. Red dotted

lines correspond to the $68 \%$ confidence intervals. The estimated threshold for the $\mathrm{MA}(6)$ of $s_{t}$ is approximately 2.46. Regimes 1 and 2 represent the regimes associated with loose and tight financial conditions, respectively. 


\section{A Capacity utilization measures}

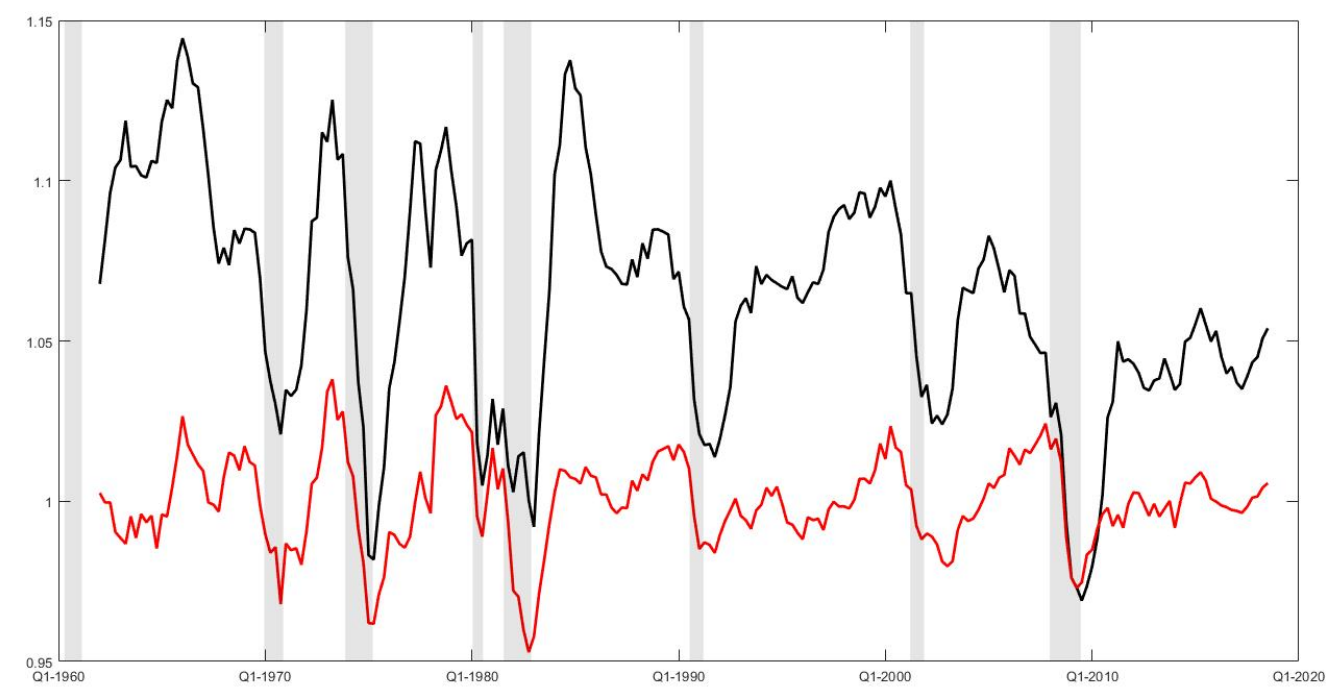

Figure A.1: USA, 1962Q1-2018Q3: Two measures of capacity utilization. Black and red lines correspond to capacity utilization measures computed using the Hamilton and Hodrick-Presott filters

(where the smoothing parameter was selected to be 1600 since we have quarterly data), respectively.

Shaded areas indicate NBER recession dates.

\section{B Econometric details}

This Appendix provides technical details regarding the implementation of dummy variables for the natural conjugate prior, the sum of coefficients prior, and the common stochastic trends prior. We also describe the implementation of the Gibbs sampling algorithm with a Metropolis Hastings step for the BTVAR. For simplicity, the notation used in this section is independent of that of the main text; and we rely on the results discussed by Blake and Mumtaz (2017).

\section{B.1 Implementing priors using dummy observations: the natural conjugate prior, the sum of coefficients prior, and the common stochastic trends prior}

A flexible approach to incorporate prior information into a VAR model is via dummy variables or artificial data. In brief, this method consists, first, in generating artificial data from the model assumed under the prior and, second, in mixing this with the actual data. The weight placed on the artificial data determines how tightly the prior is imposed.

Consider artificial data $Y_{D}$ and $X_{D}$, where: 


$$
\begin{aligned}
b_{0} & =\left(X_{D}^{\prime} X_{D}\right)^{-1}\left(X_{D}^{\prime} Y_{D}\right), \\
S & =\left(Y_{D}-X_{D} b_{0}\right)^{\prime}\left(Y_{D}-X_{D} b_{0}\right), \\
\tilde{b_{0}} & =\operatorname{vec}\left(b_{0}\right) .
\end{aligned}
$$

This means that a regression of $Y_{D}$ on $X_{D}$ yields the prior mean for the VAR coefficients and the residual sum of squares give the prior scale matrix for the error covariance matrix.

The prior is of the Normal Inverse Wishart form, which assumes a normal prior for the VAR coefficients and an inverse Wishart prior for the covariance matrix: $p(B \mid \Sigma) \sim$ $N\left(\tilde{b_{0}}, \Sigma \otimes\left(X_{D}^{\prime} X_{D}\right)^{-1}\right)$ and $p(\Sigma) \sim I W\left(S, T_{D}-K\right)$, respectively, where $T_{D}$ is the length of the artificial data and $K$ denotes the number of regressors in each equation. It can be shown that the posterior distributions for the VAR model have the following form:

$$
\begin{aligned}
& H\left(b \mid \Sigma, Y_{t}\right) \sim N\left(\operatorname{vec}\left(B^{*}\right), \Sigma \otimes\left(X^{*^{\prime}} X^{*}\right)^{-1}\right), \\
& H\left(\Sigma \mid b, Y_{t}\right) \sim I W\left(S^{*}, T^{*}\right),
\end{aligned}
$$

where $Y^{*}=\left[Y ; Y_{D}\right]$ and $X^{*}=\left[X ; X_{D}\right]$ - that is, the actual right and left hand side variables in the VAR appended by the artificial data, and $T^{*}$ represents the number of rows in $Y^{*}$. Also:

$$
\begin{aligned}
B^{*} & =\left(X^{*^{\prime}} X^{*}\right)^{-1}\left(X^{*^{\prime}} Y^{*}\right), \\
S^{*} & =\left(Y^{*}-X^{*} b\right)^{\prime}\left(Y^{*}-X^{*} b\right) .
\end{aligned}
$$

Note that the conditional posterior distribution has a simple form, and the variance of $H\left(b \mid \Sigma, Y_{t}\right)$ involves only the inversion of an $N X P+1$ matrix, where $N$ denotes the number of variables in the VAR and $P$ is the lag length, which makes this formulation much more computationally efficient.

The crucial element in this approach is to construct the artificial observations $Y_{D}$ and $X_{D}$, which need to be created by the researcher based on a set of hyper-parameters (see below). These dummy variables can then be incorporated for the natural conjugate prior, the sum of coefficients prior, and the common stochastic trends prior. In what follows, we consider a general $N$ variable VAR with $P$ lags.

The dummy observations for the natural conjugate prior can be created as follows:

$$
\begin{aligned}
Y_{D, 1}= & {\left[\begin{array}{c}
\frac{\operatorname{diag}\left(\chi_{1} \sigma_{1} \ldots \chi_{N} \sigma_{N}\right)}{\tau} \\
0_{N X(P-1) X N} \\
\ldots \\
\operatorname{diag}\left(\sigma_{1} \ldots \sigma_{N}\right) \\
\ldots \\
0_{1 X N}
\end{array}\right] } \\
X_{D, 1}= & {\left[\begin{array}{cc}
\frac{J_{P} \otimes \operatorname{diag}\left(\sigma_{1} \ldots \sigma_{N}\right)}{\tau} & 0_{N P x 1} \\
0_{N X(P-1) X N} & 0_{N X 1} \\
\ldots & \ldots \\
0_{1 X N P} & c
\end{array}\right], }
\end{aligned}
$$


where $\tau$ controls the overall tightness of the prior; $\sigma_{i}, i=1,2, \ldots, N$, are standard deviation of error terms from OLS estimates of AR regressions for each variable in the model; $\chi_{i}$ are the prior means for the coefficients on the first lags of the dependent variable; and $J_{P}=\operatorname{diag}(1,2, \ldots, P)$.

On the other hand, if the variables in the VAR have a unit root, it is possible to incorporate this information via a prior that reflects the belief that coefficients on lags of the dependent variable sum to 1 (see also Robertson and Tallman (1999)). Such a prior can be incorporated via the following dummy variables:

$$
\begin{aligned}
Y_{D, 2} & =\left[\frac{\operatorname{diag}\left(\chi_{1} \mu_{1} \ldots \chi_{N} \mu_{N}\right)}{\lambda}\right], \\
X_{D, 2} & =\left[\frac{(1,2, \ldots, P) \otimes \operatorname{diag}\left(\chi_{1} \mu_{1} \ldots \chi_{N} \mu_{N}\right)}{\lambda} 0_{N x 1}\right],
\end{aligned}
$$

where $\lambda=1 / \gamma ; \gamma$ controls the tightness of the prior (as $\gamma \rightarrow \infty$ the prior is implemented more tightly); and $\mu_{i}, i=1,2, \ldots, N$, are the sample means of each variable in the VAR.

Lastly, it is also possible to incorporate the belief that the variables in our system share a common stochastic trend via a prior constructed using the following dummy variables:

$$
\begin{aligned}
& Y_{D, 3}=\left[\begin{array}{lll}
\delta \mu_{1} & \ldots & \delta \mu_{N}
\end{array}\right], \\
& X_{D, 3}=\left[\begin{array}{lllllll}
\delta & \delta \mu_{1} & \ldots & \delta \mu_{N} & \delta \mu_{1} & \ldots & \delta \mu_{N}
\end{array}\right] \text {, }
\end{aligned}
$$

where $\delta$ controls the tightness of the prior (as $\delta \rightarrow \infty$ the prior is implemented more tightly: the series in the VAR share a common stochastic trend).

\section{B.2 Implementing a Gibbs sampling algorithm augmented with a Metropolis Hastings step}

For simplicity, let us define $Z$ and $X$ as the left and right hand side variables of the VAR, respectively, and assume that the delay parameter $d$ is known. ${ }^{18}$ The estimation process is composed of four steps:

1. Set priors. We assume $p\left(Z^{*}\right) \sim N\left(\bar{Z}^{*}, \sigma_{Z^{*}}\right)$ and use the mean of $Z_{i, t-d}$ as the initial value for $Z^{*}$.

2. Separate the data into two regimes. The first regime includes all observations such that $R_{t} \leq Z^{*}$ (call this sample $Z_{1, t}$ ); whereas the second regime includes all observations such that $R_{t}>Z^{*}$ (call this sample $Z_{2, t}$ ).

3. Sample the parameters in the VAR. We sample $b_{i}=\left\{c_{i}, \beta_{i}\right\}$ and $\Omega_{i}$ in each regime $i=1,2$. Following (B.2) and (B.3), the conditional distribution becomes:

\footnotetext{
${ }^{18}$ Chen and Lee (1995) provide the more general treatment of the algorithm where $d$ is estimated.
} 


$$
\begin{aligned}
& H\left(b_{i} \mid \Omega_{i}, Z_{t}, Z^{*}\right) \sim N\left(\operatorname{vec}\left(B_{i}^{*}\right), \Omega_{i} \otimes\left(X^{*} X^{*}\right)^{-1}\right) \\
& H\left(\Omega_{i} \mid b_{i}, Z_{t}, Z^{*}\right) \sim I W\left(S_{i}^{*}, T_{i}^{*}\right)
\end{aligned}
$$

where

$$
\begin{aligned}
B_{i}^{*} & =\left(X_{i}^{*^{\prime}} X_{i}^{*}\right)^{-1}\left(X_{i}^{*^{\prime}} z_{i}^{*}\right), \\
S_{i}^{*} & =\left(z_{i}^{*}-X_{i}^{*} b\right)^{\prime}\left(z_{i}^{*}-X_{i}^{*} b_{i}^{*}\right),
\end{aligned}
$$

and $z_{i}^{*}=\left[Z_{i, t} ; Z_{D}\right], X_{i}^{*}=\left[X_{i, t} ; X_{D}\right]$, and $Z_{D}$ and $X_{D}$ are the dummy observations that define the prior for the left and right hand side of the VAR, respectively.

4. Use a Metropolis Hastings step. We draw a new value of the threshold from the random walk $Z_{\text {new }}^{*}=Z_{\text {old }}^{*}+e, e \sim N(0, \Sigma)$, and compute the following acceptance probability:

$$
\alpha=\frac{F\left(Z \mid b_{i}, \Omega_{i}, Z_{\text {new }}^{*}\right) p\left(Z_{\text {new }}^{*}\right)}{F\left(Z \mid b_{i}, \Omega_{i}, Z_{\text {old }}^{*}\right) p\left(Z_{\text {old }}^{*}\right)}
$$

where $F\left(Z \mid b_{i}, \Omega_{i}, Z_{\text {new }}^{*}\right)$ is the likelihood of the VAR (computed as a product of the likelihood in the two regimes). Ignoring constants, the log likelihood in each regime is:

$$
\frac{T}{2} \log \left|\Omega_{i}^{-1}\right|-\frac{1}{2} \sum_{t=1}^{T}\left[\left(Z_{i, t}-X_{i, t} \tilde{b}_{i}\right)^{\prime} \Omega_{i}^{-1}\left(Z_{i, t}-X_{i, t} \tilde{b}_{i}\right)\right],
$$

where $\tilde{b}_{i}$ is equivalent to $b_{i}$ but has been reshaped to be conformable with $X_{i, t}$. We draw a number $u$ from the standard uniform distribution $u \sim U(0,1)$, if $u<\alpha$ then we accept the parameter $\left(Z_{\text {new }}^{*}\right)$, otherwise we keep the old one $\left(Z_{\text {old }}^{*}\right)$.

\section{Linear Bayesian Vector Autoregression}

Below we report the IRFs obtained from the BVAR model using the following Cholesky ordering of variables: $s_{t} \rightarrow v_{t} \rightarrow \pi_{t} \rightarrow i_{t}$. We also incorporated priors via dummy variables as described in Appendix B; but the Bayesian simulation method employed in the linear

estimation is a Gibbs sampling algorithm (without the Metropolis Hastings step), so the acceptance probability $\alpha$ (described in appendix B) is equal to 1 in this estimation. 

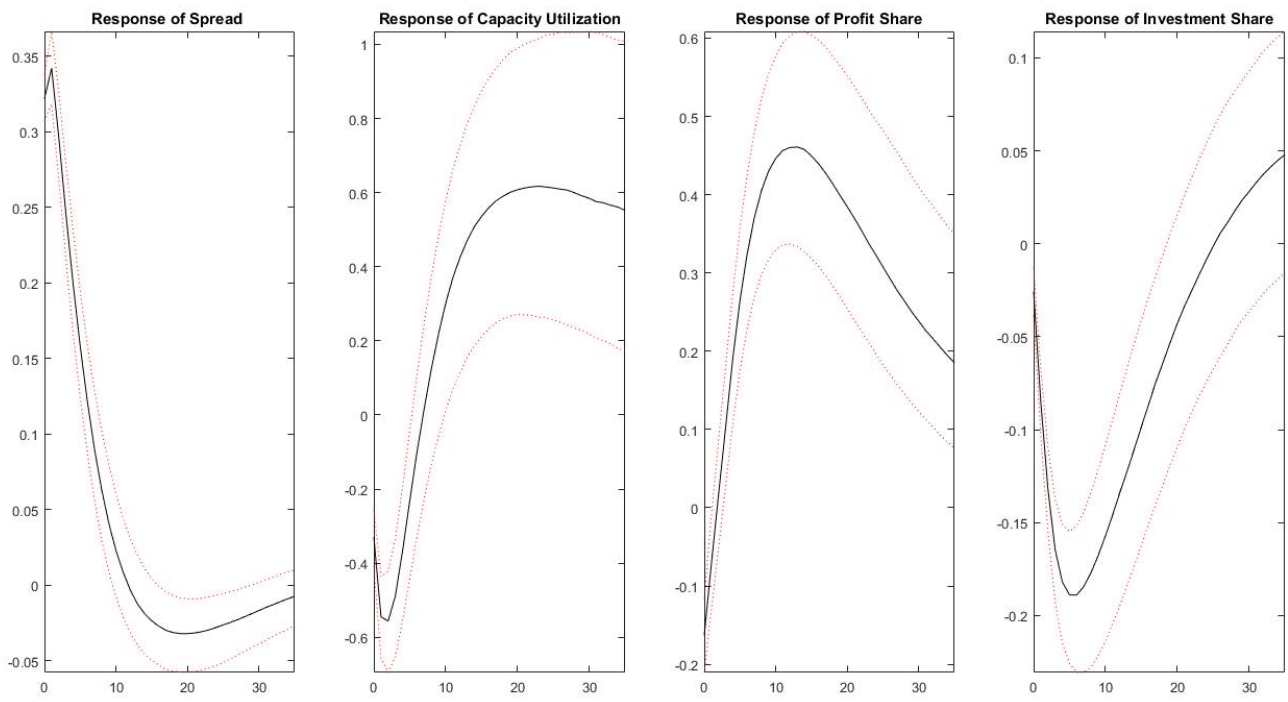

Figure C.1: USA, 1962Q1-2018Q3. Impulse-response functions obtained from a one standard deviation shock to spread $s_{t}$. The horizontal axis shows quarters ahead in all figures. Red dotted lines correspond to the $68 \%$ confidence intervals.
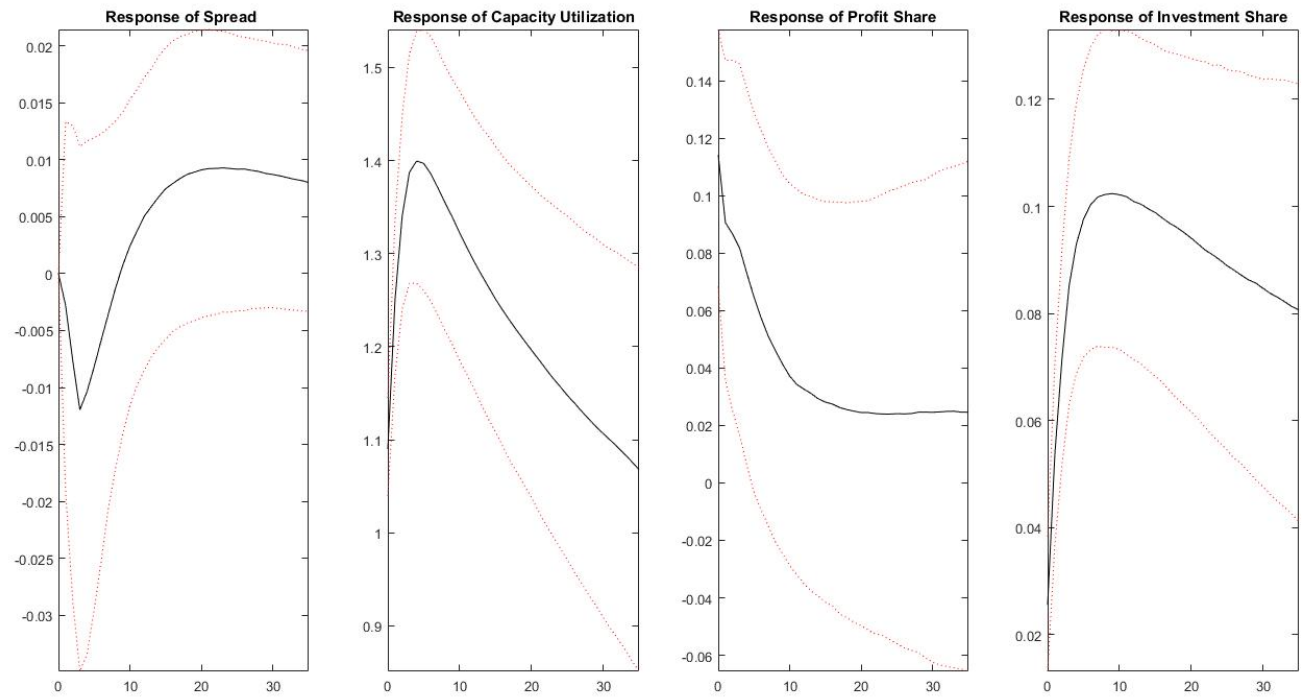

Figure C.2: USA, 1962Q1-2018Q3. Impulse-response functions obtained from a one standard deviation shock to capacity utilization $v_{t}$. The horizontal axis shows quarters ahead in all figures. Red dotted lines correspond to the $68 \%$ confidence intervals. 

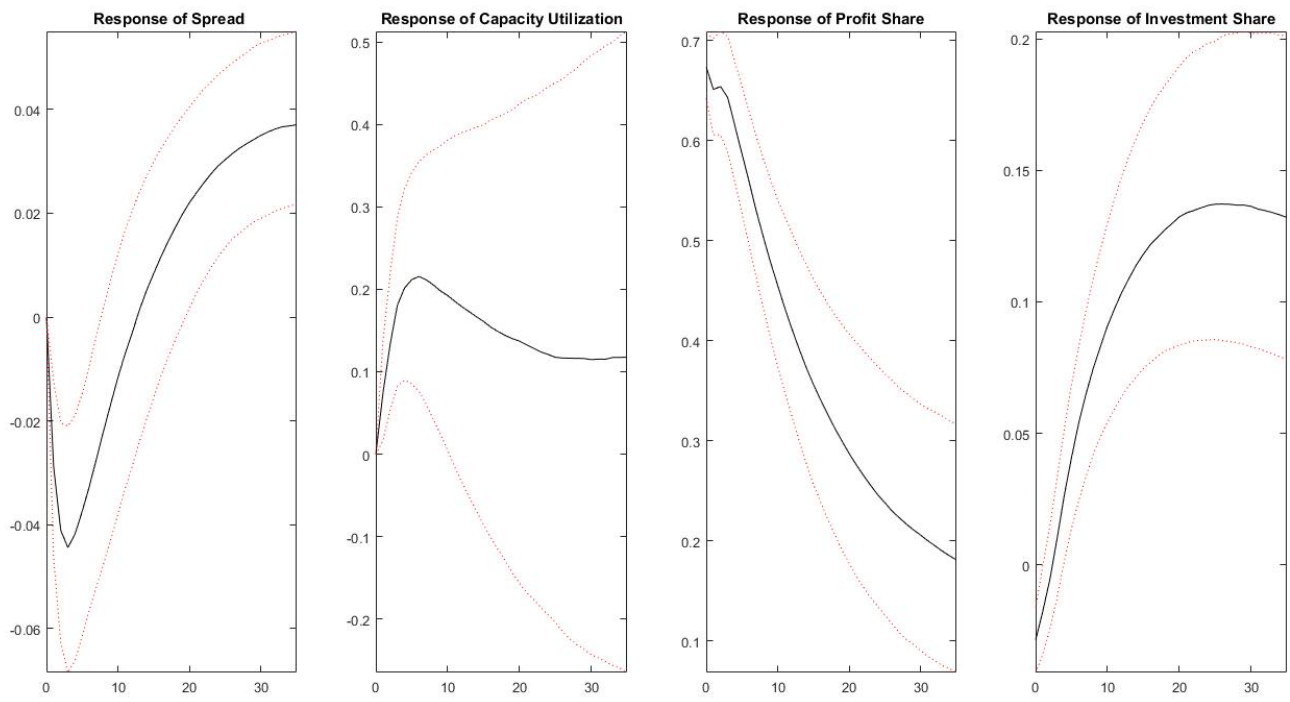

Figure C.3: USA, 1962Q1-2018Q3. Impulse-response functions obtained from a one standard deviation shock to profit share of income $\pi_{t}$. The horizontal axis shows quarters ahead in all figures. Red dotted lines correspond to the $68 \%$ confidence intervals.
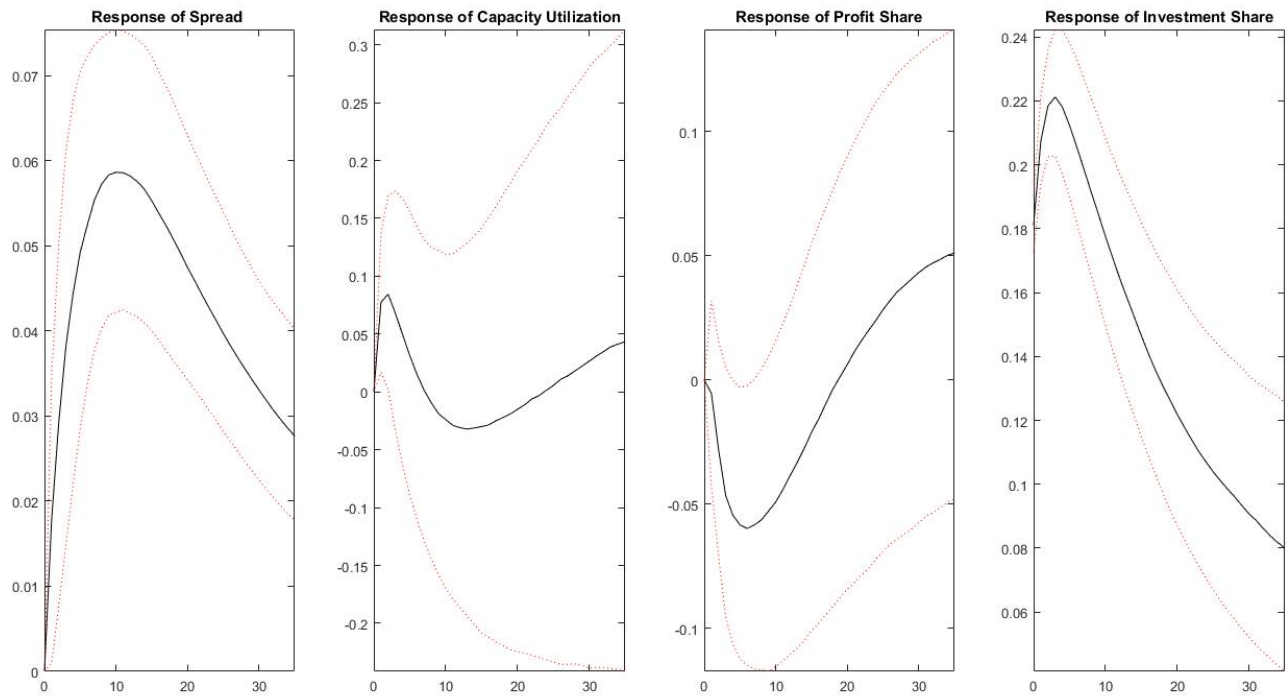

Figure C.4: USA, 1962Q1-2018Q3. Impulse-response functions obtained from a one standard deviation shock to investment share of income $i_{t}$. The horizontal axis shows quarters ahead in all figures. Red dotted lines correspond to the $68 \%$ confidence intervals. 


\section{Convergence of the Bayesian sampling algorithm for the Threshold Vector Autoregression}

Here we present evidence of convergence of the Gibbs sampling algorithm with a Metropolis Hastings step by reporting the traceplots corresponding to the BTVAR coefficients, $\beta_{i}$, and the standard deviations of the respective BTVAR variance-covariance matrices, $\sigma_{i}, i=$ Regime 1, Regime 2, for the periods 1962Q1-2018Q1 and 1980Q1-2018Q1.
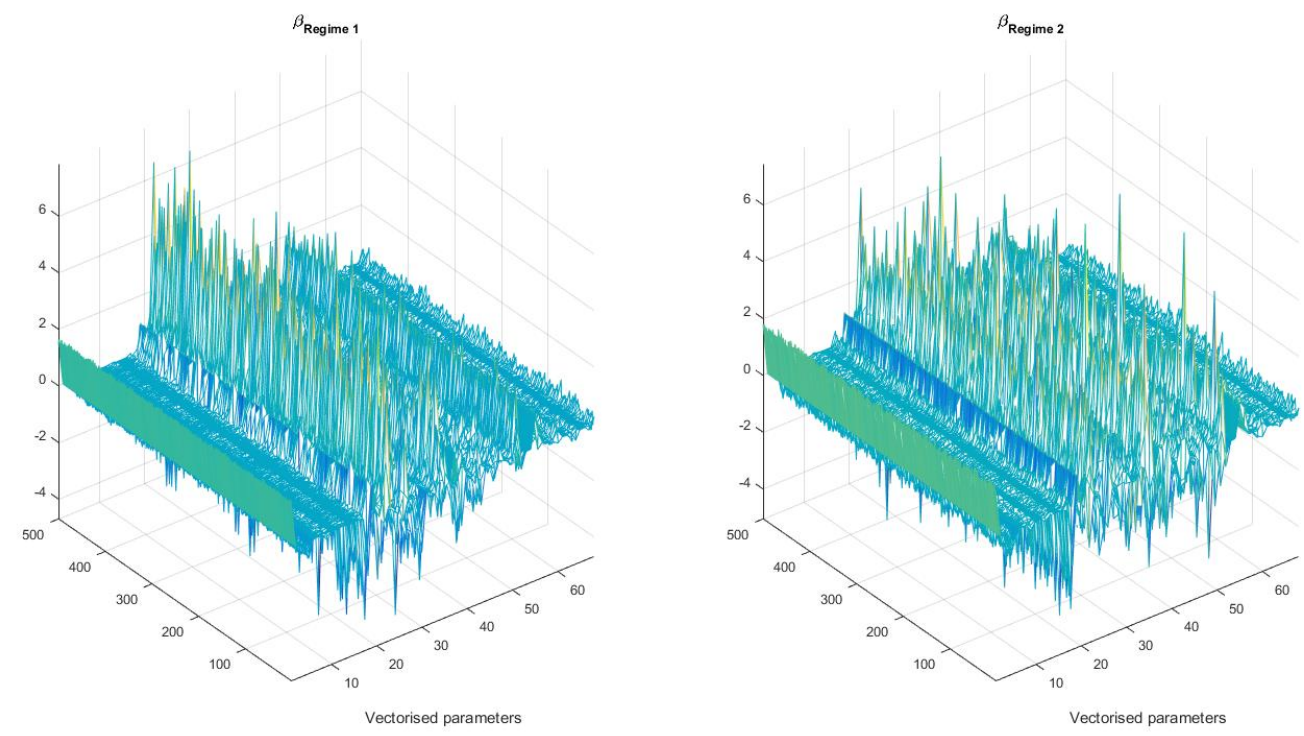

Figure D.1: USA, 1962Q1-2018Q3. Convergence of the BTVAR coefficients for the two regimes.
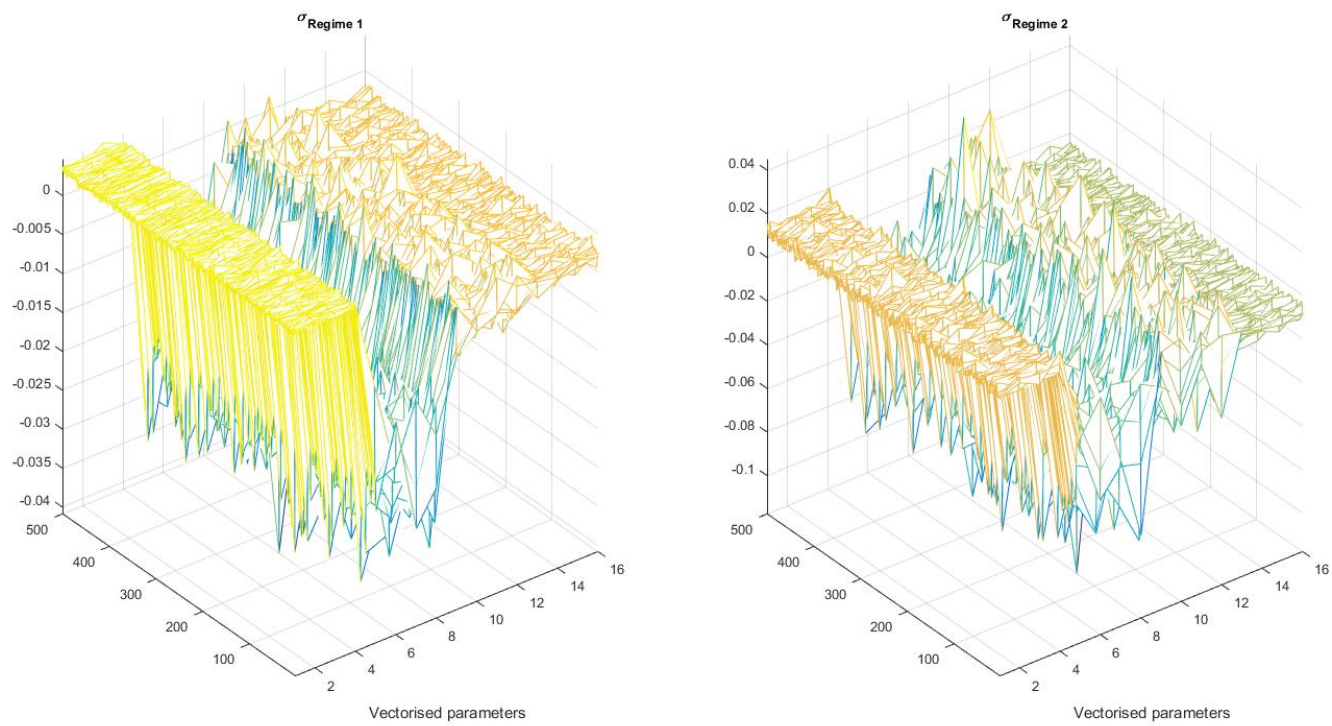

Figure D.2: USA, 1962Q1-2018Q3. Convergence of the BTVAR variance-covariance matrices for the two regimes. 

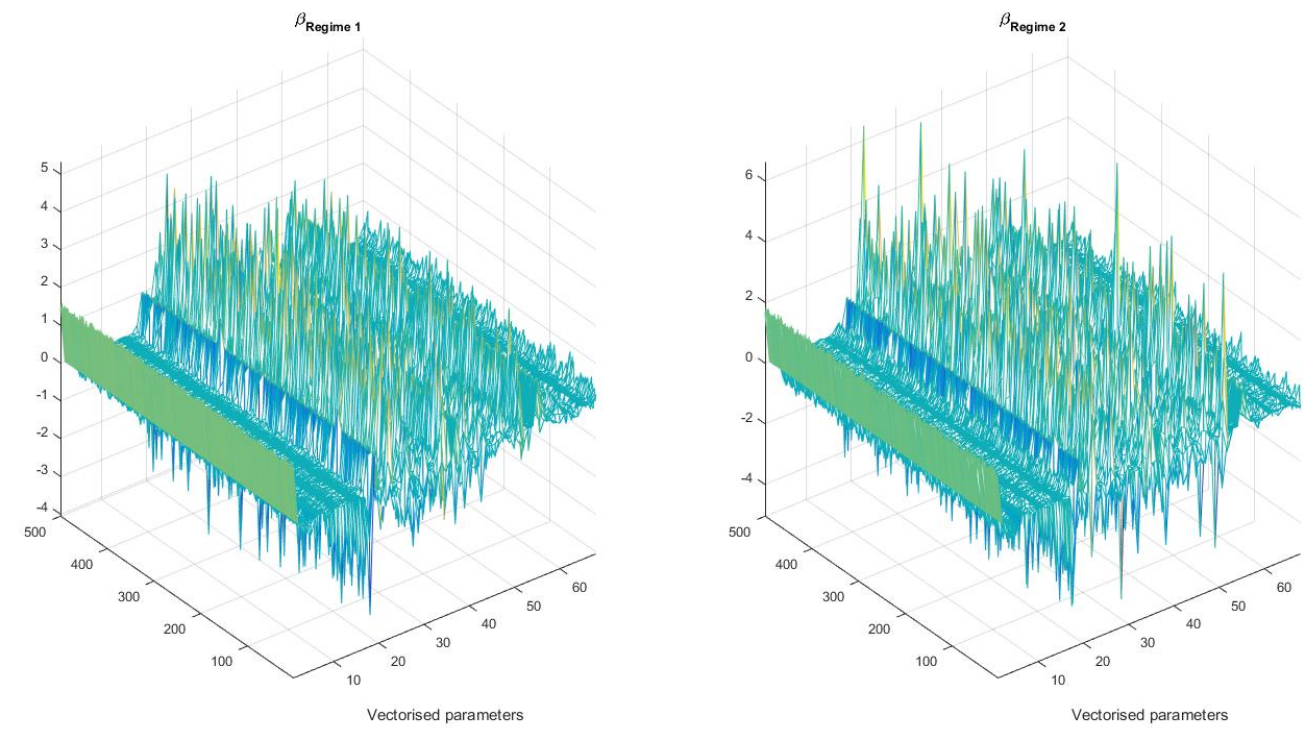

Figure D.3: USA, 1980Q1-2018Q3. Convergence of the BTVAR coefficients for the two regimes.
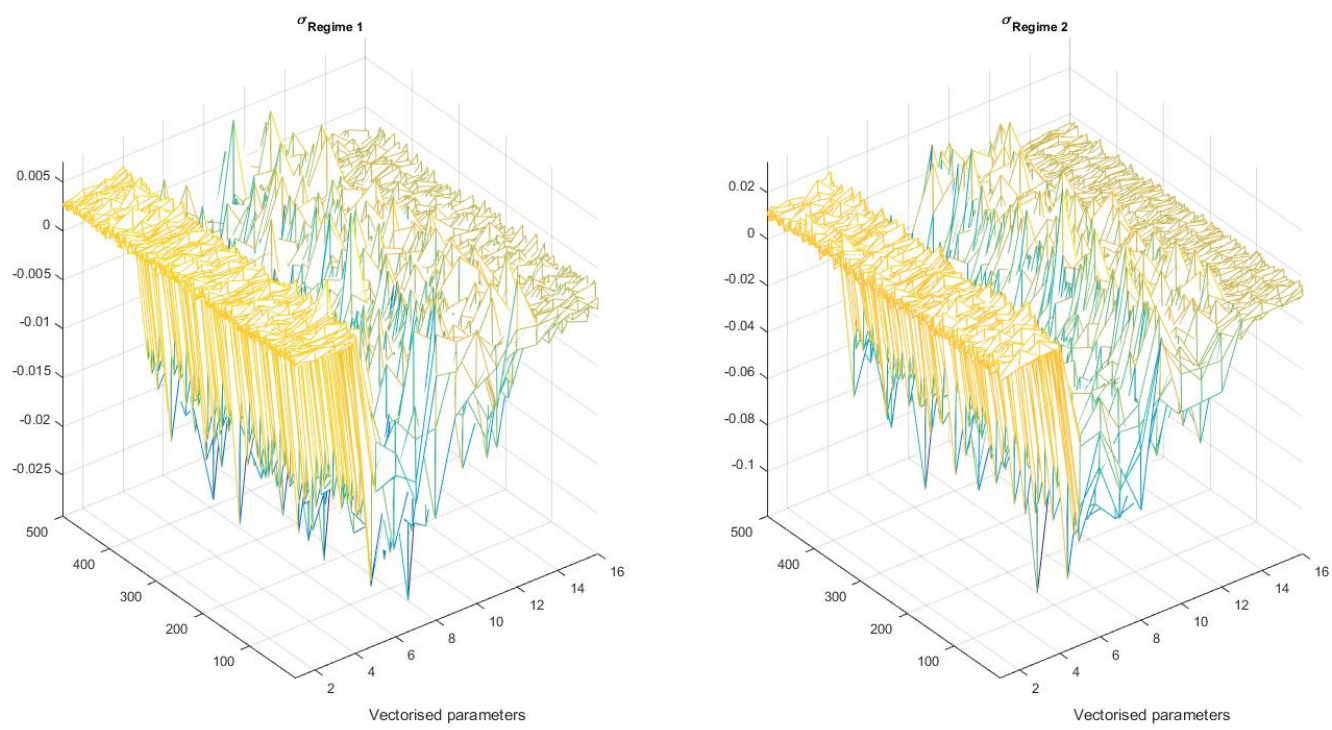

Figure D.4: USA, 1980Q1-2018Q3. Convergence of the BTVAR variance-covariance matrices for the two regimes.

\section{E Bayesian Threshold Vector Autoregression for the period 1980Q1-2018Q3}

The IRFs obtained from the Cholesky ordering $s_{t} \rightarrow v_{t} \rightarrow \pi_{t} \rightarrow i_{t}$ are reported in Figures E.1 through E.4; while the results derived from the alternative Cholesky ordering of variables $v_{t}$ $\rightarrow s_{t} \rightarrow \pi_{t} \rightarrow i_{t}$ are presented in Figures E.5 through E.8. 

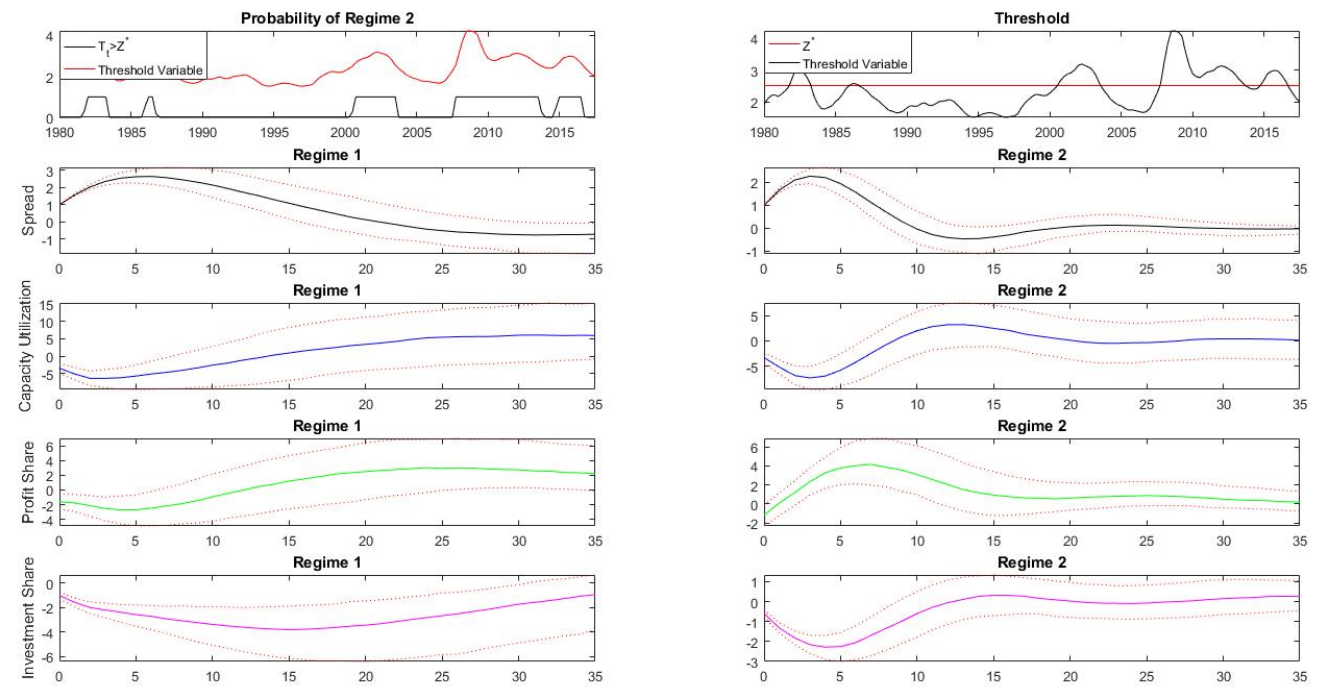

Figure E.1: USA, 1980Q1-2018Q3. Impulse-response functions obtained from a one standard deviation shock to spread $s_{t}$. The ordering of the variables in the BTVAR is $s_{t} \rightarrow v_{t} \rightarrow$ $\pi_{t} \rightarrow i_{t}$. The horizontal axis shows quarters ahead in all figures. Red dotted lines correspond to the $68 \%$ confidence intervals. The estimated threshold for the MA(6) of $s_{t}$ is approximately 2.46 . Regimes 1 and 2 represent the regimes associated with loose and tight financial conditions, respectively.
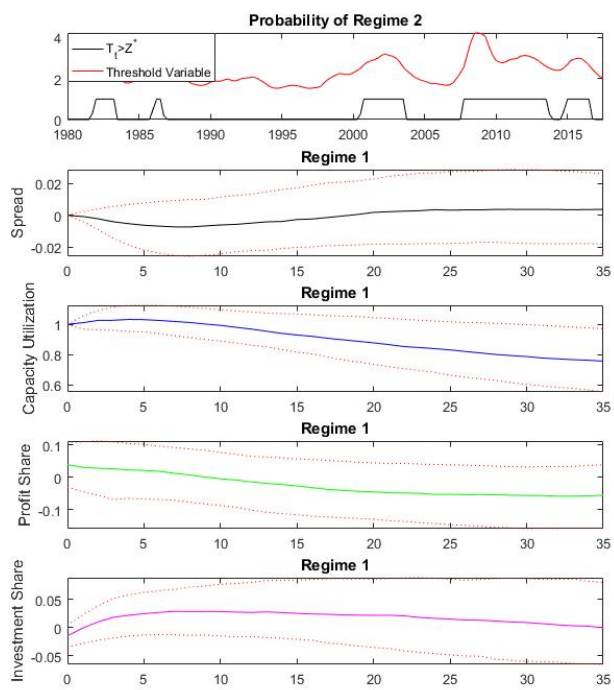
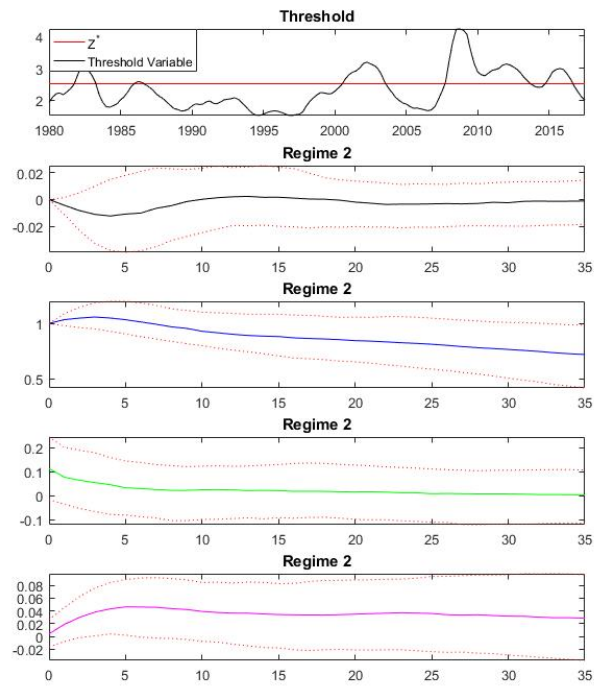

Figure E.2: USA, 1980Q1-2018Q3. Impulse-response functions obtained from a one standard deviation shock to capacity utilization $v_{t}$. The ordering of the variables in the BTVAR is $s_{t} \rightarrow v_{t} \rightarrow \pi_{t} \rightarrow i_{t}$. The horizontal axis shows quarters ahead in all figures. Red dotted lines correspond to the $68 \%$ confidence intervals. The estimated threshold for the MA(6) of $s_{t}$ is approximately

2.46. Regimes 1 and 2 represent the regimes associated with loose and tight financial conditions, respectively. 

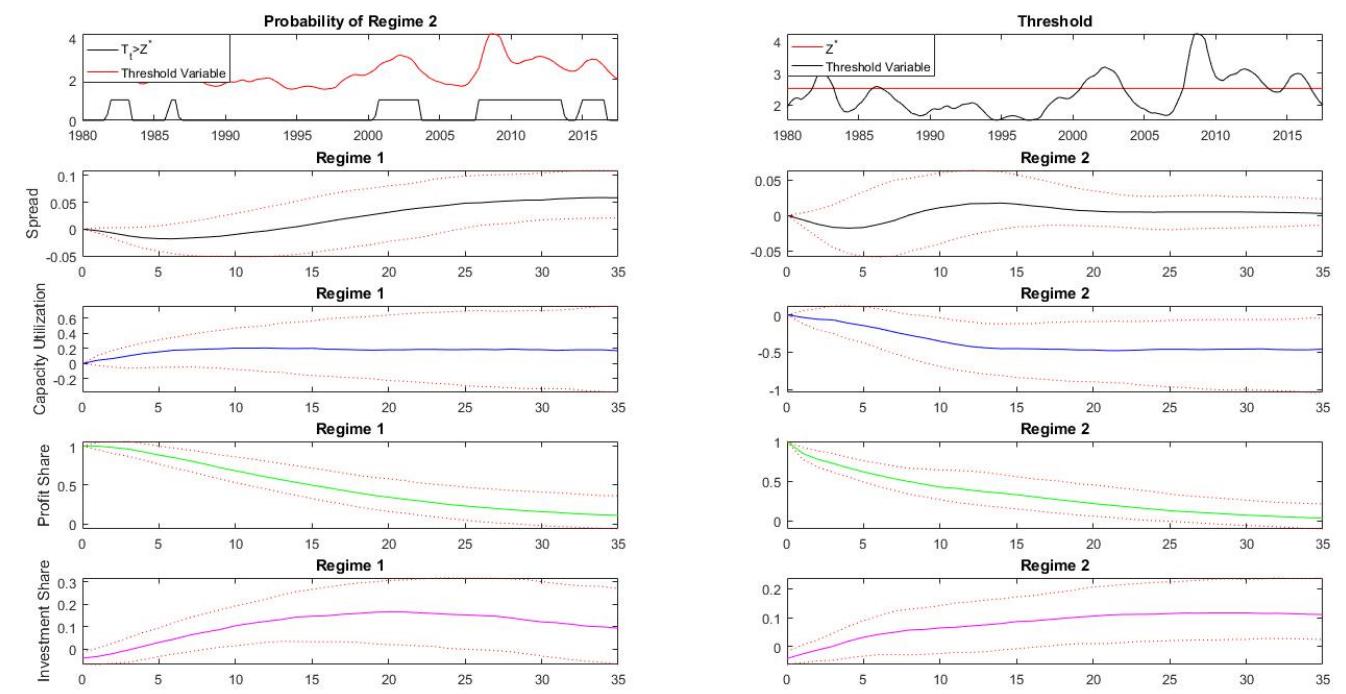

Figure E.3: USA, 1980Q1-2018Q3. Impulse-response functions obtained from a one standard deviation shock to profit share of income $\pi_{t}$. The ordering of the variables in the BTVAR is $s_{t} \rightarrow v_{t} \rightarrow \pi_{t} \rightarrow i_{t}$. The horizontal axis shows quarters ahead in all figures. Red dotted lines correspond to the $68 \%$ confidence intervals. The estimated threshold for the MA(6) of $s_{t}$ is approximately

2.46. Regimes 1 and 2 represent the regimes associated with loose and tight financial conditions, respectively.
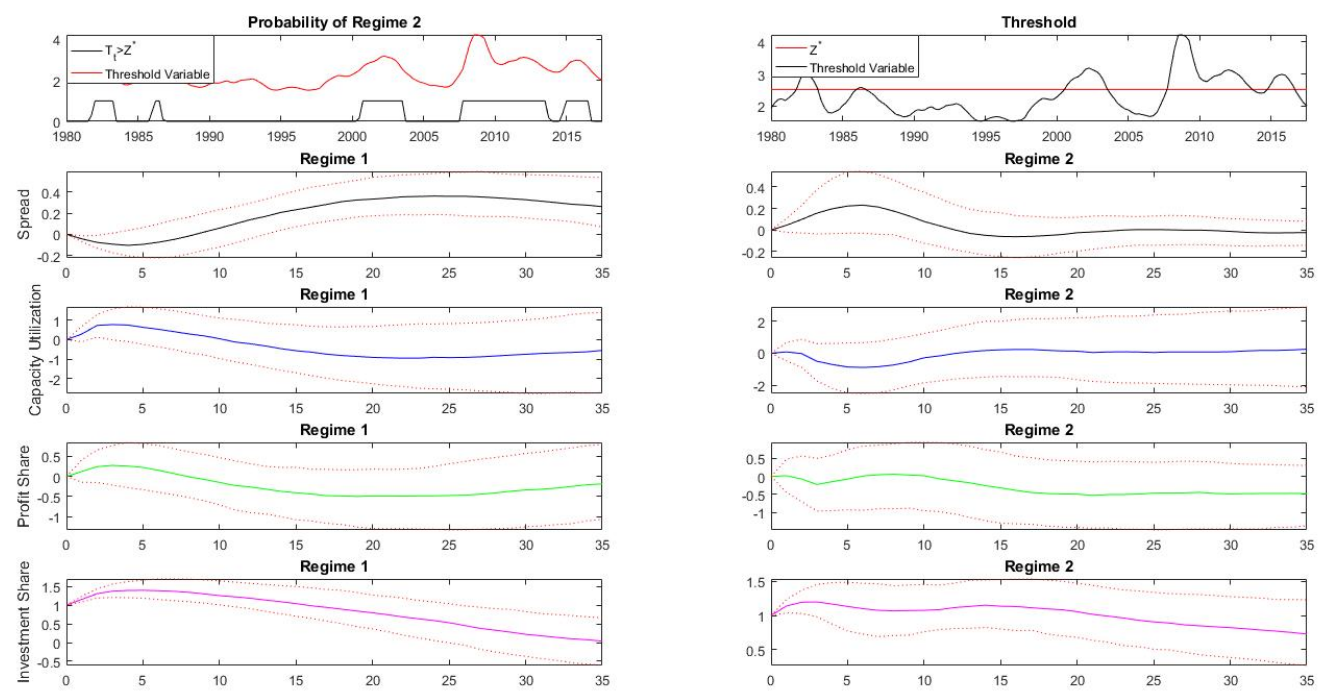

Figure E.4: USA, 1980Q1-2018Q3. Impulse-response functions obtained from a one standard deviation shock to investment share of income $i_{t}$. The ordering of the variables in the BTVAR is $s_{t} \rightarrow v_{t} \rightarrow \pi_{t} \rightarrow i_{t}$. The horizontal axis shows quarters ahead in all figures. Red dotted

lines correspond to the $68 \%$ confidence intervals. The estimated threshold for the MA(6) of $s_{t}$ is approximately 2.46. Regimes 1 and 2 represent the regimes associated with loose and tight financial conditions, respectively. 

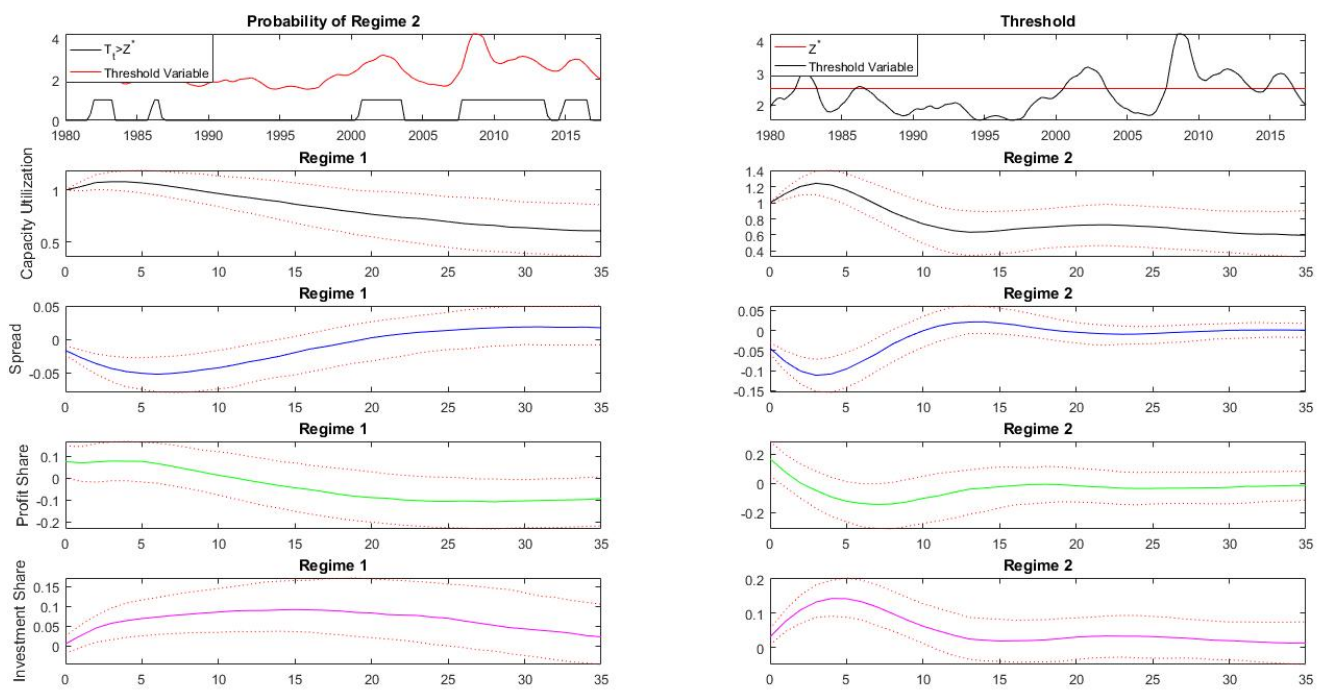

Figure E.5: USA, 1980Q1-2018Q3. Impulse-response functions obtained from a one standard deviation shock to capacity utilization $v_{t}$. The ordering of the variables in the BTVAR is $v_{t} \rightarrow s_{t} \rightarrow \pi_{t} \rightarrow i_{t}$. The horizontal axis shows quarters ahead in all figures. Red dotted lines correspond to the $68 \%$ confidence intervals. The estimated threshold for the MA(6) of $s_{t}$ is approximately

2.46. Regimes 1 and 2 represent the regimes associated with loose and tight financial conditions, respectively.
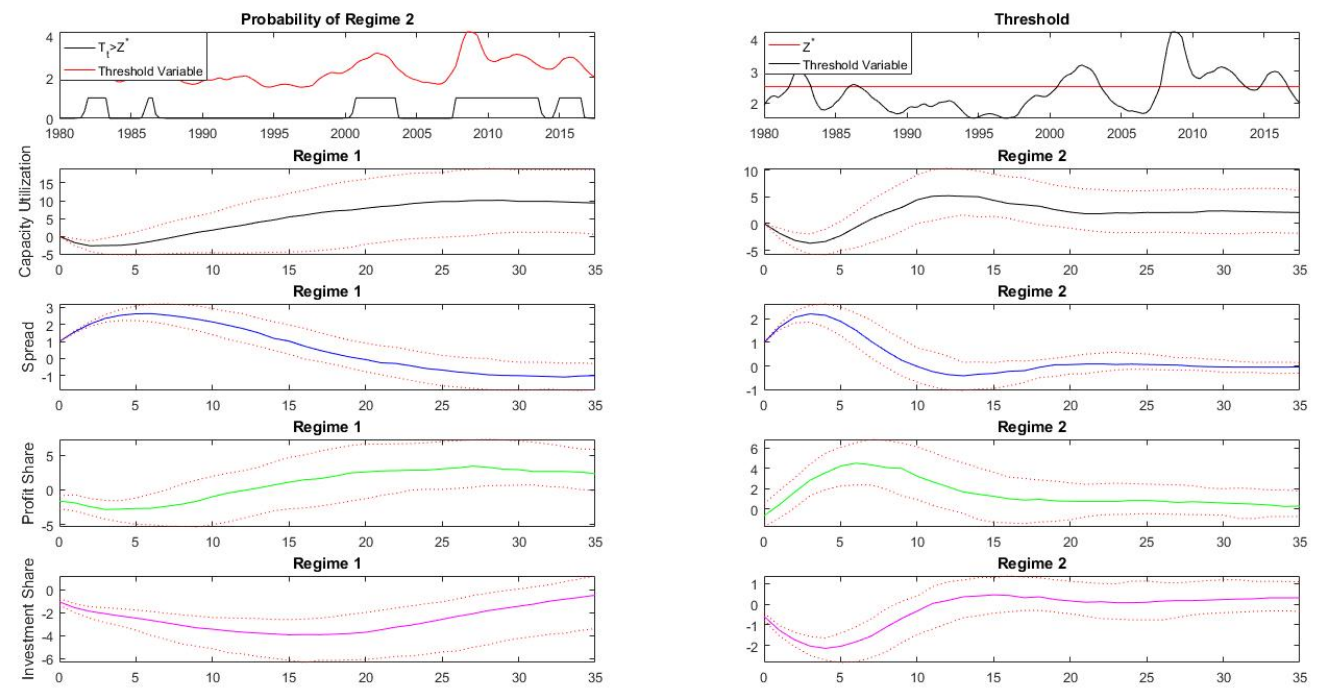

Figure E.6: USA, 1980Q1-2018Q3. Impulse-response functions obtained from a one standard deviation shock to spread $s_{t}$. The ordering of the variables in the BTVAR is $v_{t} \rightarrow s_{t} \rightarrow$ $\pi_{t} \rightarrow i_{t}$. The horizontal axis shows quarters ahead in all figures. Red dotted lines correspond to the $68 \%$ confidence intervals. The estimated threshold for the $\mathrm{MA}(6)$ of $s_{t}$ is approximately 2.46 . Regimes 1 and 2 represent the regimes associated with loose and tight financial conditions, respectively. 

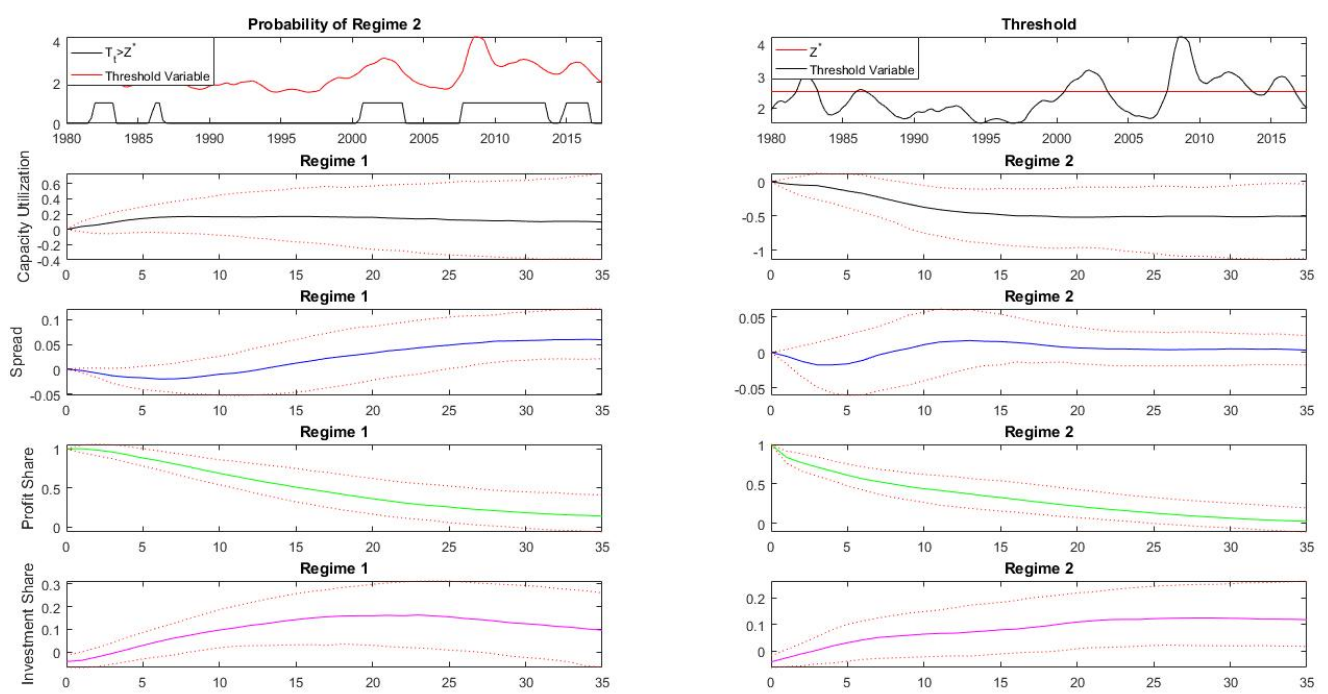

Figure E.7: USA, 1980Q1-2018Q3. Impulse-response functions obtained from a one standard deviation shock to profit share of income $\pi_{t}$. The ordering of the variables in the BTVAR is $v_{t} \rightarrow s_{t} \rightarrow \pi_{t} \rightarrow i_{t}$. The horizontal axis shows quarters ahead in all figures. Red dotted lines correspond to the $68 \%$ confidence intervals. The estimated threshold for the MA(6) of $s_{t}$ is approximately

2.46. Regimes 1 and 2 represent the regimes associated with loose and tight financial conditions, respectively.
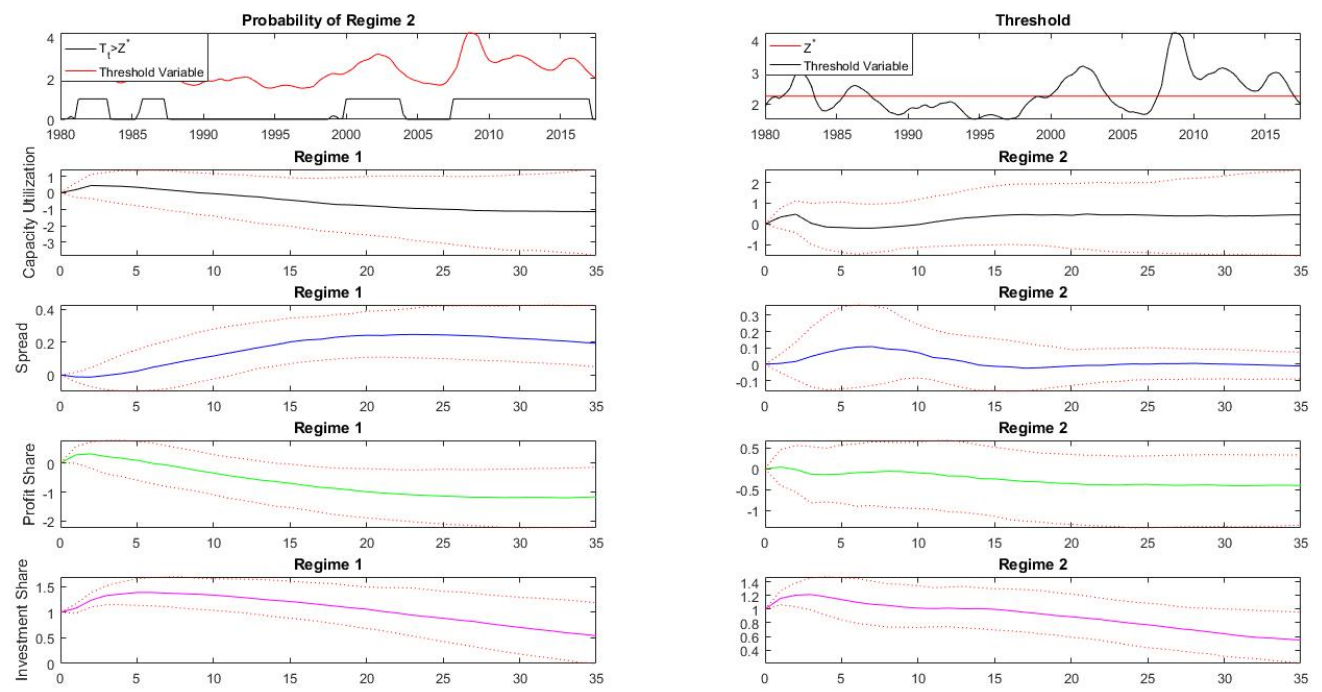

Figure E.8: USA, 1980Q1-2018Q3. Impulse-response functions obtained from a one standard deviation shock to investment share of income $i_{t}$. The ordering of the variables in the BTVAR is $v_{t} \rightarrow s_{t} \rightarrow \pi_{t} \rightarrow i_{t}$. The horizontal axis shows quarters ahead in all figures. Red dotted

lines correspond to the $68 \%$ confidence intervals. The estimated threshold for the $\mathrm{MA}(6)$ of $s_{t}$ is approximately 2.46. Regimes 1 and 2 represent the regimes associated with loose and tight financial conditions, respectively. 